\title{
A GENETICAL STUDY OF FLOWER FORM AND FLOWER COLOR IN PHLOX DRUMMONDII
}

\author{
JAMES P. KELLY \\ Department of Botany, Pennsylvania State College, State College, Pennsylvania
}

[Received December 9, 1919]

TABLE OF CONTENTS

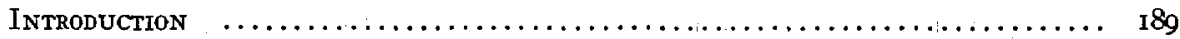

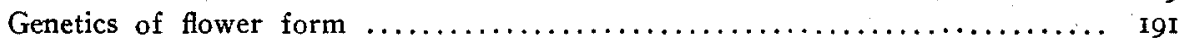

The "Star Phloxes" $\ldots \ldots \ldots \ldots \ldots \ldots \ldots \ldots \ldots \ldots \ldots \ldots \ldots \ldots \ldots$ Ig1

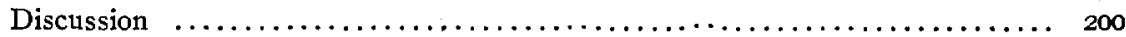

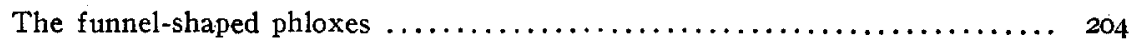

Genetics of flower color .................................... 209

Factor differences involved when type with completely white flowers (A) was crossed with type having dark-eyed white-bladed flowers (B)-the $A B$

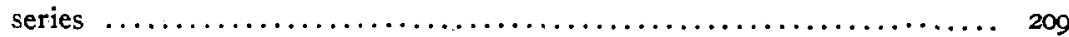

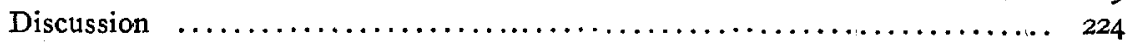

The crossing of brilliant "red" or carmine (E) by pure cream (F) - The EF

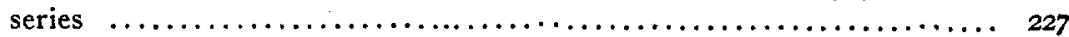

The crossing of white-eyed pink (J) and completely white (A) - the JA series 235 Some simpler cases of color inheritance in Phlox Drummondii............. 242

The crossing of white-eyed Tyrian rose (P) and white-eyed pink (J) .... 242

The genetic relationship of white (A) and cream (F) ............... 243

The genetic relationship of white with dark eye (B) and cream without dark

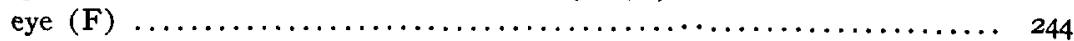

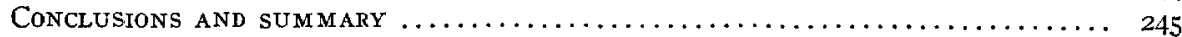

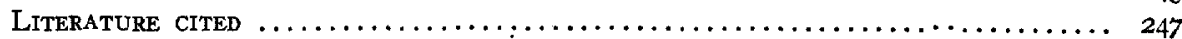

INTRODUCTION

Of the thousands of species of plants known to science, surely of not more than a half dozen can the student of heredity claim to have a fair knowledge. Hereditary study of the modern Mendelian sort is dependent on "the presence of differential unit characters" (SHULL I9IO), and it is somewhat surprising that in the case of Phlox Drummondii with its large number of strains possessing marked differentiating characters no extensive analysis has yet been presented. The author has already discussed the variation in this species (KELLY 1915), having pointed out that there are forms that are tall, some that are half-dwarf, and some that are dwarf; some are large-flowered and some small-flowered; the inflorescence may be loose and spreading or rounded and dense; the flower may be single, half-double, or fully double; the fully opened flower may be salver-shaped or funnel-shaped; the colors have a wide range from 
white and cream through pinks, lilacs, roses, purples and reds, to almost black; the flowers may have dark centers or eyes, or white centers; the corolla lobes may be wide and markedly overlapping or narrow; the corolla lobes may be entire or variously laciniated. One laciniate type (var. fimbriata) was many years ago reported to be inconstant (SPRENGER I888). The I9I4 catalogue of HAAGE and Sch mIDT, a large German seed-firm, offered for sale 173 varieties within this single species. This wealth of variation is known to have occurred subsequent to 1835 , and without the aid, as far as the evidence goes, of crossing outside of the species.

Only one bit of experimental work on the genetics of Phlox Drummondii has thus far appeared, namely, a paper by A. W. GILBERT (I915), who carried three crosses through the $F_{2}$ generation, and assumed five factors to explain his observations: A dark-eye factor, a blue factor, a red factor, an intensifying. factor, and a cream factor. The question of factor interactions was raised by his work, as he expressly made cream dependent on the presence of the dark-eye factor (presumably the same dark-eye factor that is necessary for the production of an anthocyanin eye); and his intensifying factor functioned visibly only when the red was present he also tacitly assumed (as the factorial formulae in his tables prove) an important interaction effect between the blue and red factors; thus in one place it appears that the blue factor alone gave rise to a lilac-colored flower, the red alone to a pink, but these two factors together were supposed to give a deep (full-)-colored carmine type. GrLbert carried none of his experiments beyond the $F_{2}$ generation and confirmation of his formulae is therefore lacking. A preponderance of white-flowered plants following one of his crossings was "unaccounted for."

The present paper is offered as a further contribution to the genetical analysis of the species. It is based on experimental data secured chiefly while pursuing graduate work in the Department of Biology of PRINCEton University ${ }^{1}$; the author is indebted to Dr. G. H. Shuld, under whose auspices the work was carried on, for suggestions and an encouraging interest in the progress of the work; and to Dr. E. N. Harvey for enlightenment on the chemical aspects of the color problems. Acknowledgments are also due to Prof. R. A. EMERson, of Cornell UniverSITY, for valuable criticisms. The paper will concern itself first with certain variations in the form of the flower; then with an analysis of color conditions in the flower.

\footnotetext{
3 Much necessary preliminary work had been done at the Pennsylvania State Coliege.
} 


\section{GENETICS OF FLOWER FORM \\ The "Star Phloxes"}

In the spring of 1914 the writer sowed seeds of what the seedsman called "Star Phlox" and was impressed by the decided variation exhibited in the flowers when the plants came to maturity; one plant showed the flowers entire-edged and gave similar offspring, others bore: flowers that were variously fringed or toothed. A study of the character and history of these variations was undertaken.

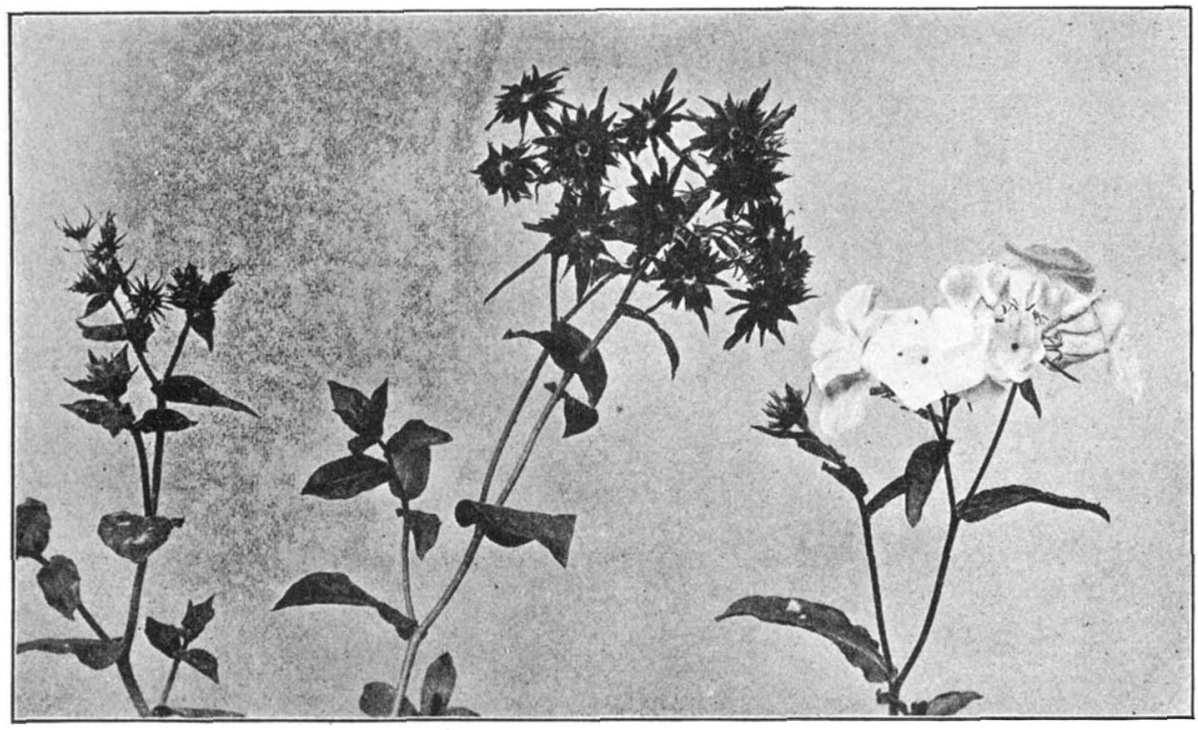

Figure I.-To the left, a cuspidata plant (type L). To the right, a plant with entireedged flowers (type $A$ ). In the center, the $F_{1}$ hybrid of $A$ and $L$ (this hybrid is of the fimbriata type). Cuspidata and fimbriata are "star phloxes."

As elsewhere pointed out (Kelly I915) Phlox Drummondii, of which species the "Star Phloxes" are a variety or varieties, was first introduced to cultivation in 1835 and the original phloxes had entire-margined flowers. A perusal of horticultural literature published since 1835 shows that the varieties with fringed or toothed corolla segments, i.e., the "Star Phloxes," were unknown till about I887 when they seem to have created quite a stir in German horticultural circles; in that year the firm of Martin Grashoff was awarded a certificate of merit for introducing two novelties, both of which are grouped together under the popular name of "Star Phloxes." The flowers of both novelties had fringed or incised edges. Wittmack (I888) named these P. Drummondii 
var. fimbriata and P. Drummondii var. cuspidata. On a cursory examination cuspidata can be distinguished from fimbriata by the smaller body of the flower, meaning by body the non-incised residuum of the

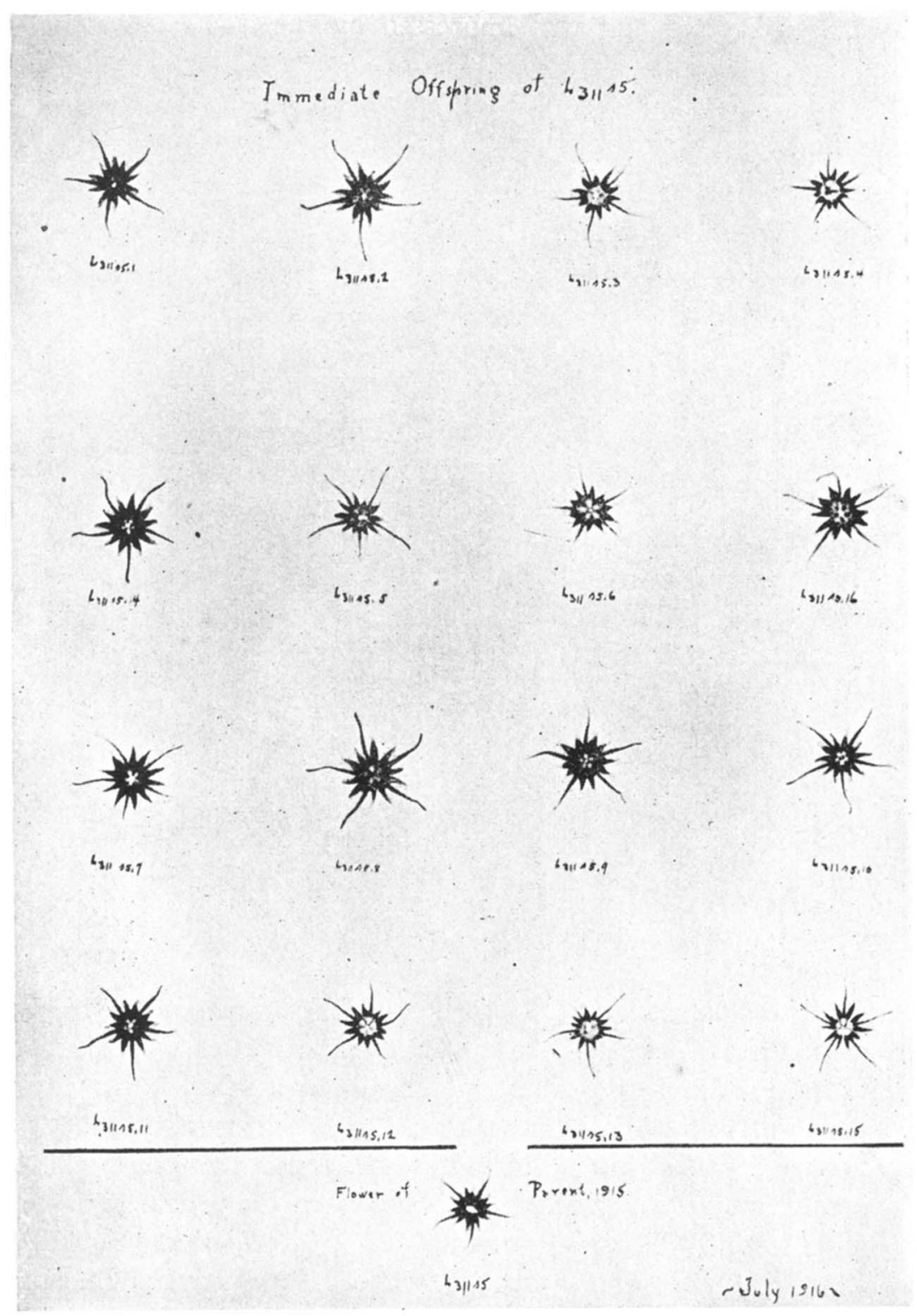

FIGURE 2.-The 16 flowers above represent a family of cuspidata plants; each of the $\mathbf{1 6}$ flowers is from a separate plant. Below, a flower from the parent of this family. 
flower limb immediately surrounding the throat. Figures 2 and 5 show the contrast at a glance. This body, of course, will be in the five sections or lobes characterizing Phlox flowers of every kind; in fimbriata and cuspidata, however, each lobe bears three teeth, the middle tooth in fimbriata being one to four times the length of the side teeth, while in cuspidata it is perhaps six times the length of the side teeth.

Complete or at least a high degree of constancy through seed should ordinarily characterize a variety of an annual plant like Phlox Drummondii. A voice was soon raised against the listing of fimbriata as a good variety. C. SPREnGer (I888) grew plants, evidently from commercial seed, in his garden near Naples in 1888 and found but I9 fimbriata plants in a total of 94 ; he deemed this insufficient stability to warrant fimbriata being given varietal rank. SPRENGer assented, however, to the listing of cuspidata as a good variety. That these objections to fimbriata as a variety proved fruitless is seen from BRAND's (I907) treatment of the Polemoniaceae in "Das Pflanzenreich." BRAND mentions both var. fimbriata and var. cuspidata in his treatment of the types of Phlox Drummondii and he moreover gives himself as authority for having once raised both types to full specific rank.

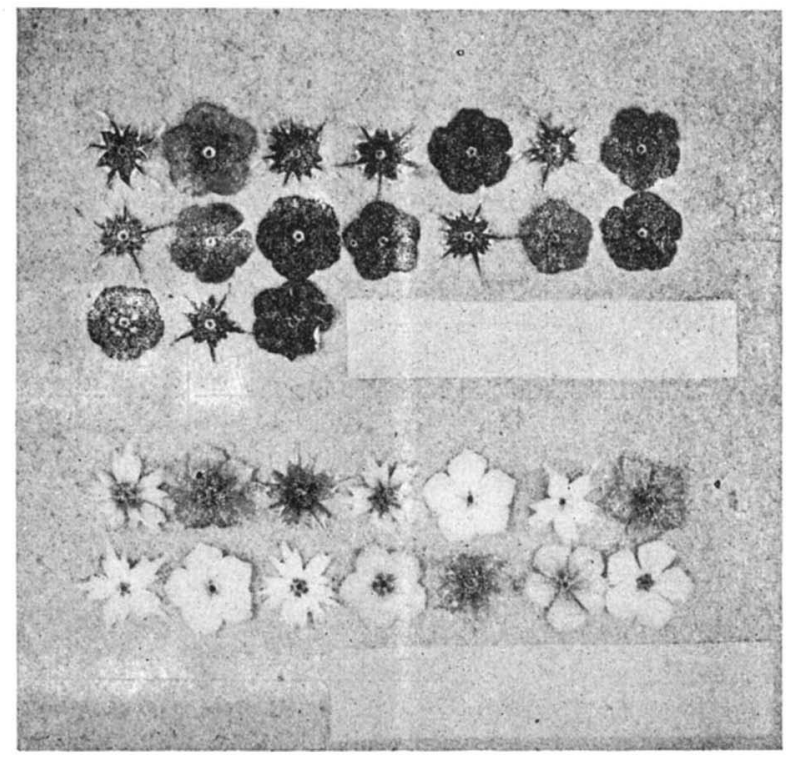

Figure 3.-Two families derived from back-crossing of fimbriata to entire. Each flower represents a single plant. 
The experimental results of the writer have made clear the interrelationships of cuspidata, fimbriata, and the entire-edged flowers. One cuspidata plant of ${ }_{191} 5\left(\mathrm{~L}_{311.5}\right)$ was the ancestor of all the cuspidatas used in these experiments; there have descended directly from it, in spite of the difficulties of securing selfed seed, a total of 4I plants, all, without exception, of cuspidata type. Four families descended from segregate cuspidata plants of known hybrid extraction were also unexceptionally cuspidata. As far as tested, then, cuspidata is constant for its peculiar flower form. Figure 2 shows a flower of $L_{311,5}$ and one from each of its 16 progeny. Plants with floral periphery entire have been found to give, on inbreeding, only progeny with entire margins.

The crossing of cuspidata plants with those whose flowers were entire has been made in different seasons with results that have been always the same,--the $F_{1}$ hybrids have been of the fimbriata type. This particular hybridization has been made 12 times giving rise to a total progeny of $94 \mathrm{~F}_{1}$ plants, all of which bore fimbriata flowers (see figure $\mathrm{I}$ for the parental and $F_{1}$ types).

On back-crossing fimbriata with the entire-edged type there appear only fimbriata and entire in about equal numbers. Several back-crosses of this kind have been made, yielding a total of I2 I progeny, of which 52 were fimbriata and 69 bore flowers that were entire (see figure 3 and table I).

TABLE I

Tabular presentation of back-crosses of fimbriata to entire.

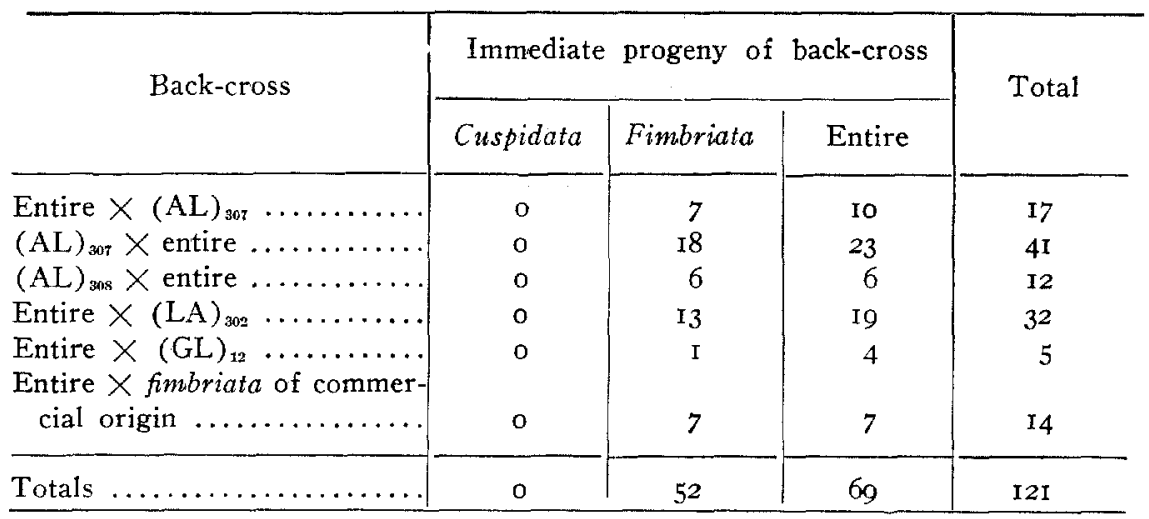

Considerable data have accumulated concerning the character of the progeny of self-fertilized fimbriata plants of known origin. The total number of offspring thus produced through several summers has been 
706. Of these I79 bore entire flowers, 353 were fimbriatas, and 174 were cuspidatas (see table 2 and figures 6 and 7 ).

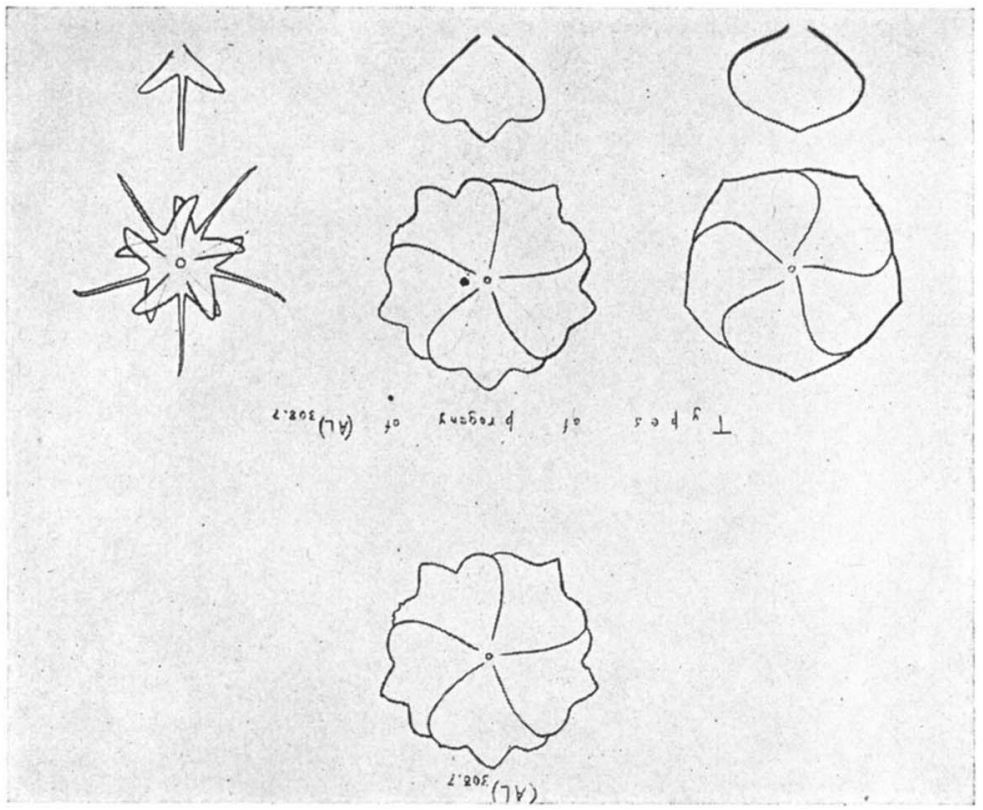

FIGURE 4.-Above, diagram of a shallowly incised fimbriata flower. The three flowers on the second line are diagrams of all the flower types occurring among the progeny (by selfing) of a shallowly incised fimbriata plant. The lowermost line gives diagrams of single corolla segments of each of the types. Compare with diagrams in figure 5 and note that shallowly laciniated plants are associated with entire-lobed sibs that are wide-lobed, and with cuspidate sibs of a peculiar type.

The experimental results set forth demonstrate very clearly that in Pholox Drummondii the type with entire-margined flowers differs from the cuspidata type by a single pair of genes; that there is a lack of dominance of the differentiating gene, which results in the production of a distinct heterozygous type called fimbriata; and that this $\mathrm{F}_{1}$ form, fimbriata, can give but 50 percent of fimbriata offspring (25 percent being cuspidata and 25 percent entire) in accordance with simple Mendelian expectations. The bearing of this conclusion on the taxonomic position assigned by BRAND to fimbriata is obvious; fimbriata should not have specific rank; even varietal rank should be denied it; it should be designated as an ever-splitting hybrid form like the Blue Andalusian fowl.

Segregates from fimbriata plants have been tested, with results which support the general conclusion reached in the preceding paragraph. 
TABLE 2

Composition of progenies of self-fertilised fimbriata.

\begin{tabular}{|c|c|c|c|c|}
\hline Pedigree number & Entire & Fimbriata & Cuspidata & Total \\
\hline$(\mathrm{LJ}), \ldots \ldots \ldots \ldots$ & 2 & 3 & I & 6 \\
\hline$(\mathrm{LJ})_{100} \ldots \ldots \ldots \ldots$ & I & I & 3 & 5 \\
\hline$(G L)_{s} \quad \ldots \ldots \ldots \ldots$ & 2 & o & 3 & 5 \\
\hline$(G L)_{12} \ldots \ldots \ldots \ldots$ & 5 & 8 & 6 & 19 \\
\hline$(\mathrm{GL})_{12.5} \ldots \ldots \ldots \ldots$ & 3 & 9 & 5 & I7 \\
\hline$(\mathrm{GL})_{12.6} \ldots \ldots \ldots \ldots$ & 3 & 3 & I & 7 \\
\hline$(\mathrm{AL})_{821} \quad \ldots \ldots \ldots \ldots$ & 13 & 43 & I4 & 70 \\
\hline$(\mathrm{AL})_{334} \ldots \ldots \ldots \ldots$ & 6 & 9 & 4 & I9 \\
\hline$(A L)_{888} \quad \ldots \ldots \ldots \ldots$ & 3 & II & 5 & I9 \\
\hline$(L A)_{302} \quad \ldots \ldots \ldots \ldots$ & I9 & 25 & I2 & 56 \\
\hline$(\mathrm{AL})_{30 \pi} \ldots \ldots \ldots \ldots$ & 4 & I3 & 4 & $2 \mathrm{I}$ \\
\hline$(\mathrm{AL})_{331.65} \quad \ldots \ldots \ldots$ & 19 & 29 & I6 & 64 \\
\hline$[C(A L)]_{1} \ldots \ldots$ & 16 & 43 & 23 & 82 \\
\hline$[B(L A)]_{1} \ldots \ldots \ldots$ & II & 26 & ro & 47 \\
\hline$(\mathrm{AL})_{331.5} \quad \ldots \ldots \ldots \ldots$ & I & 2 & 2 & 5 \\
\hline$(\mathrm{AL})_{30 s .7} \ldots \ldots \ldots \ldots$ & 13 & $2 \mathrm{I}$ & I I & 45 \\
\hline$(\mathrm{AL})_{102} \quad \ldots \ldots \ldots \ldots$ & 30 & $5 \mathrm{I}$ & 28 & $\log$ \\
\hline$[\mathrm{A}(\mathrm{L} A)]_{1} \quad \ldots \ldots \ldots$ & 8 & I4 & 2 & 24 \\
\hline$(A L)_{931.54} \ldots \ldots \ldots$ & 5 & 9 & 6 & 20 \\
\hline$(A L)_{331.29} \quad \ldots \ldots \ldots$ & 13 & 27 & I3 & 53 \\
\hline$(\mathrm{AL})_{102} \quad \ldots \ldots \ldots \ldots$ & 2 & 6 & 5 & I3 \\
\hline Totals $\ldots . . . \ldots \ldots$ & 179 & 353 & 174 & 706 \\
\hline
\end{tabular}

Eight entire-flowered segregates gave families averaging over 24 offspring each, every one of which bore entire-margined flowers (see figure 9). Four cuspidata segregates produced families averaging over $4^{\mathrm{I}}$ progeny each, every one of which was cuspidata; no entire flowers occurred nor any that were fimbriata (see figure 8).

A glance at the culture conveys the impression that the fimbriate and cuspidate flower shapes are independent of color; they can be transferred from one color type to another. A narrow white or whitish band found invariably bounding the outer edge of the cuspidata and fimbriata flowers, however, has never been found shifted to segregates with entireedged flowers.

Concerning the variability of the types it should be said that it is to be expected in the case of any series of multiple structures like the collection of flowers on a plant that variations will occur. The flowers on a fimbriata plant may show fairly noticeable variation but it is not difficult to recognize a typical flower for each plant and then easily to separate the fimbriate from the cuspidate types, or types of fimbriates from one another. 

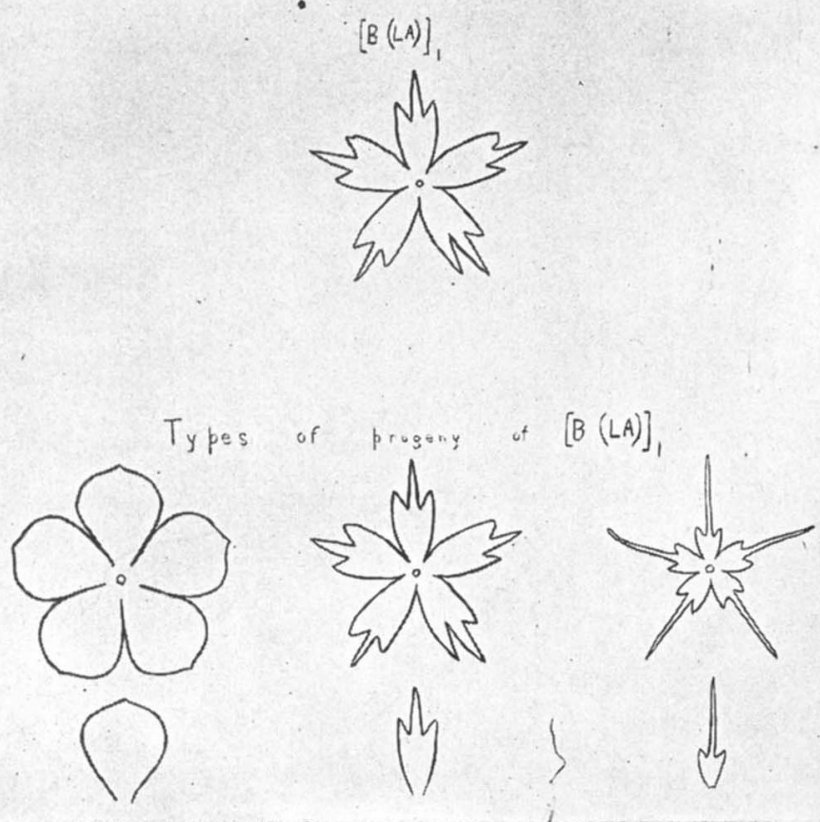

FIgURE 5.-Above is a diagram of a flower of a sharply and rather deeply incised fimbriata parent. The three flowers on the second line are diagrams of all the flower types appearing among its offspring. The lowermost line gives diagrams of single corolla lobes of these types. Compare with figure 4.

Some of the differences in the case of the fimbriatas are obviously genetic. In one $\mathrm{F}_{3}$ family descended from a shallowly fringed fimbriata parent, designated (AL) $)_{308.7}$, there were I I cuspidatas, 2 I fimbriatas, and I 3 entires; all of the 2I fimbriatas were shallowly fringed like the parent, as shown in figures 4 and 6 . The non-incised central residuum of the flower of these fimbriatas was nearly as extensive as the blade in the flowers of their entire sibs; the teeth were very short. An examination of the rest of the family revealed that the shallow type of fimbriata was associated with cuspidata sibs of a unique kind (see the I I plants represented to the left in figure 6); the lateral teeth on each corolla lobe were longer and heavier than in the (typical) cuspidata first described, and project out more or less tangentially rather than radially; this odd type of cuspidata on another occasion was found to be true-breeding. Also accompanying the shallow fimbriata was a breadth of corolla lobe in the entire sibs that was so great that they decidedly overlapped.

Another $\mathrm{F}_{3}$ family, descended from a fimbriata plant designated $[B(L A)]_{1}$, made interesting comparison with the foregoing one. It com- 


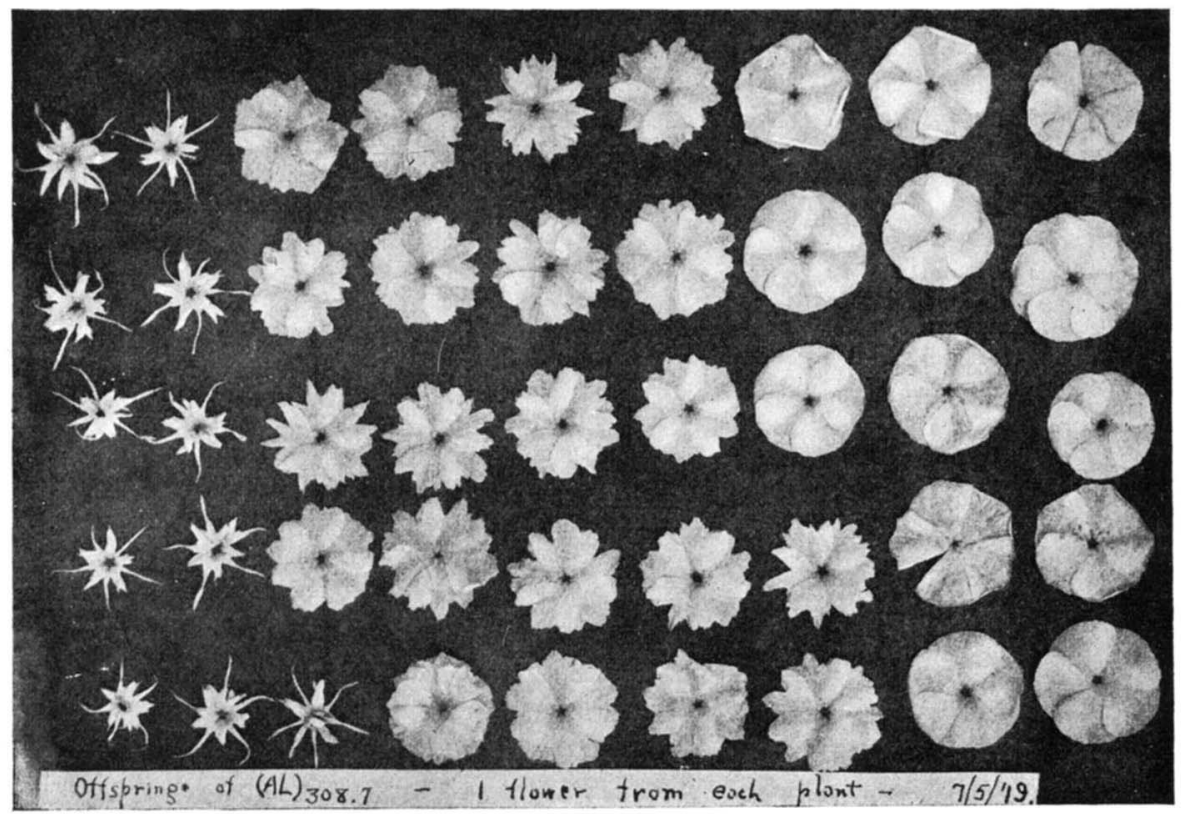

FIGURE 6.-A single family descended from a fimbriata parent whose flowers were shallowly incised like the fimbriates here shown. Note that the sibs of shallow fimbriatas are wide-lobed entires and the (new) type of cuspidata whose side teeth extend more or less tangentially. One flower from each plant of the family.

prised Io cuspidata, 26 fimbriatas, and I i entires (see figures 5 and 7 ). The fimbriatas throughout were more deeply incised and resembled their parent; the middle tooth of each corolla lobe was longer in comparison to its adjoining side teeth than was the case in the shallow fimbriatas discussed in the preceding paragraph. Occurring as sibs with this more incised fimbriata was the typical cuspidata whose side teeth were short and extending radially, and a narrow-lobed type of entire.

The two fimbriata types just described evidently differed because of some modifying factor or factors that are non-specific; these affect the condition both of the cuspidata and of the entire. Other families show a mixture of types.

An extreme and unusual variation arose on a port:on of a single fimbriata plant in I918; a few of the flowers had entire margins, these being confined to a small part of the plant which was otherwise fimbriata. A bud sport was suspected and seed from the entire-flowered branch was separately sown in 1919. It gave rise to 2 entire-flowered plants, 6 fimbriata and 3 cuspidata plants, and none of the fimbriatas again bore 


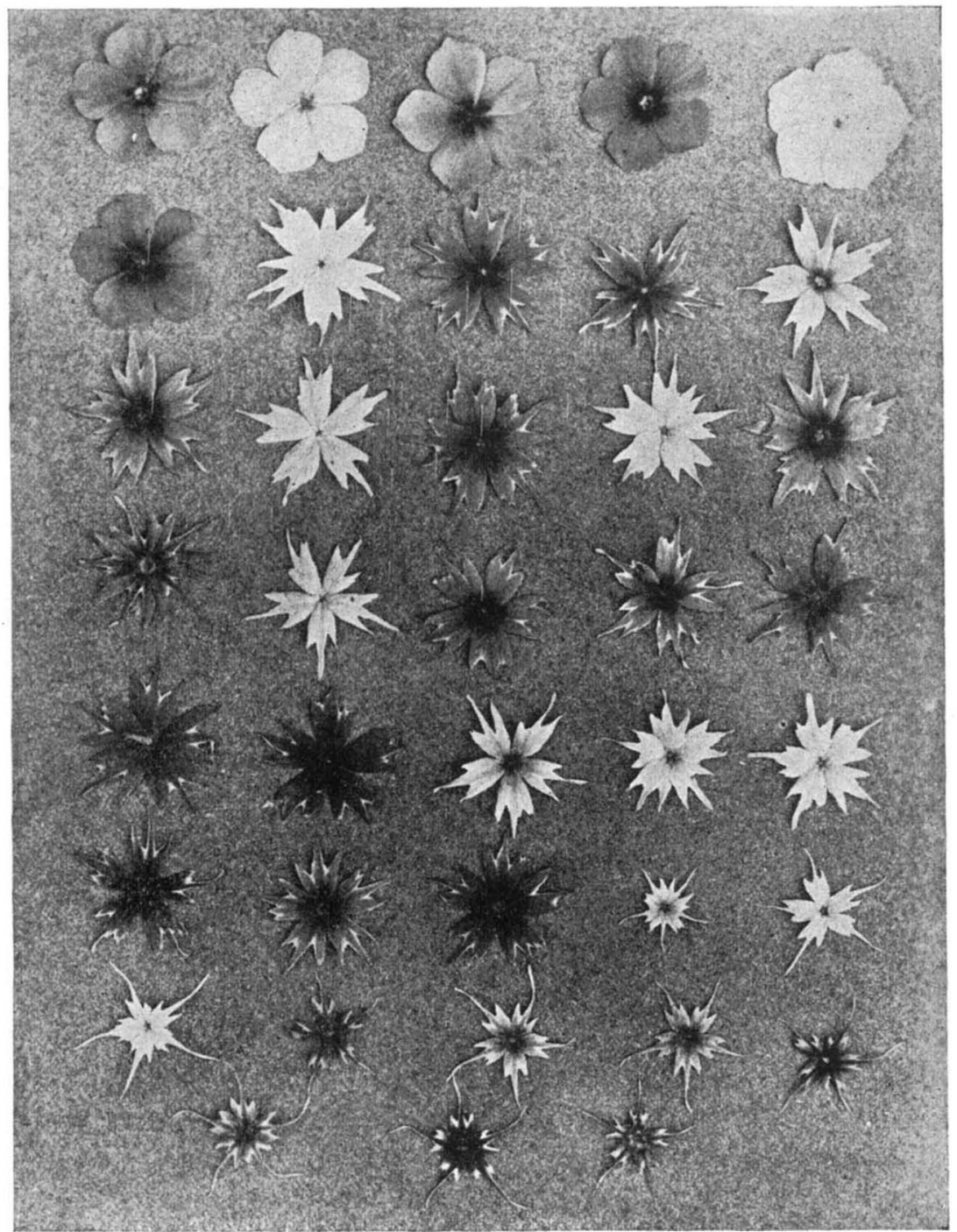

FIgURE 7.-All of the flowers of this figure represent a single family which was derived from a fimbriata parent of type diagrammed at top of figure 5. Each flower was from a separate plant and was typical of the plant. Attention is directed to the narrow-lobed condition of the entire flowers and to the types of the fimbriata and cuspidata sibs associated with narrow-lobed entires. (Nine sibs of these plants-5 entires and 4 fimbriatas-bloomed later and were not included in the photograph.) 
entire flowers. The I9I9 data might be taken to indicate that the variation to the entire condition was non-genetic, that it was merely a remarkably wide fluctuation. We should keep in mind, however, that the epidermis in the entire-flowered branch might have become, through a mutation or a somatic segregation in the dermatogen, genetically distinct from the other floral tissues. A constitutional change that was so localized would not be transmitted by the germ-cells of the flower since these are hypodermal in origin. The epidermis leaves no progeny, in other words, and its hereditary composition cannot be ascertained. This reservation is important since structural features normally exist in Phlox petals which point to the epidermis playing an important direct rôle in determining the flower form.

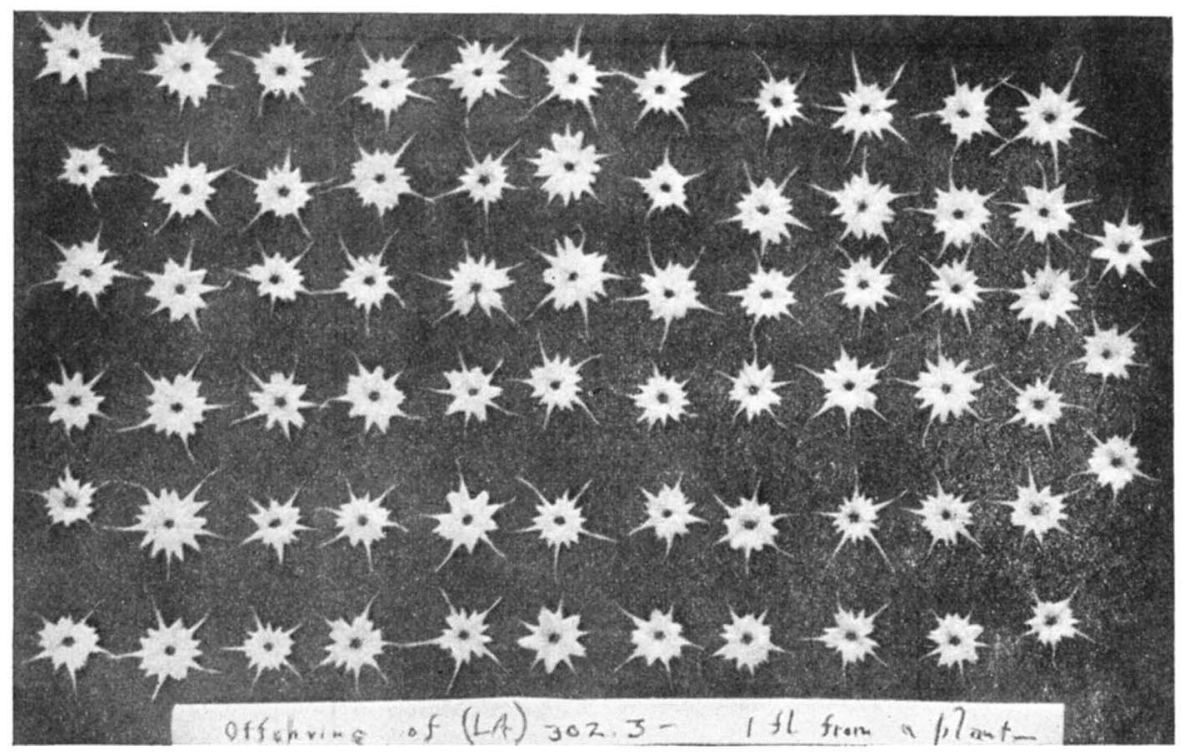

Figure 8.-An entire family descended from a cuspidata segregate. Each flower represents a separate plant and is typical for it.

\section{Discussion}

It is characteristic of announcements of novelties in gardening or horticultural publications that the exact circumstances surrounding the origin of a form are omitted. The account by Witтmack (1888) in the Gartenflora says that cuspidata arose from fimbriata by selection; as to how fimbriata arose nothing is written. The existence of fimbriata prior to cuspidata is to be noted, however; this points to the origin by mutation 
of the cuspidata gene in a locus of a single chromosome, presenting the new mutant character in its heterozygous expression, the fimbriata type; and one selection among the progeny of the original fimbriata should have sufficed to isolate the cuspidata.

C. Sprenger (I888), who seems to have been an apothecary living near Naples, claims to have seen the spontaneous origin of cuspidata in his garden in April, I888, (presumably directly, without intervening fimbriata stage) but the statement should be accepted with reservation. SpREnger, by his own account, had received Phlox seeds from Quedlinburg, where cuspidata and fimbriata were first presented to the trade; it seems very possible that a stray cuspidata seed was what gave rise to his unexpected plant. The origin of cuspidata directly would most probably have required two similar mutations in distinct but homologous chromosomes.

DE VRIES (I900) lists several plants which exhibit characters completely recessive in the $F_{1}$ hybrids and reappearing in about 25 percent of the offspring of the following generation. The laciniation or fringing of the petals of a celandine (Chelidonium) proved such a character when crossed with another celandine having entire petals.

Considering plant organs homologous with petals, some data furnished by CoRRENS (I9I2) in nettle hybrids, by LEAKE (I9II) with cotton hybrids, and by GREgory (I9I I) with Primula hybrids, are pertinent. CoRRENS crossed a rettle with serrated leaves and one with nearly entire leaves and found serration to be a dominant character; the $\mathrm{F}_{2}$ gave a ratio of 3 serrated to I non-serrated. The incised nature of the floral leaves in celandine behaves as a recessive trait in hybrids; that of the foliage leaves in the nettle is a dominant trait; while the incised floral leaves of Phlox is an intermediate. LEAKE'S work concerned the genetic relationship of two types of foliage leaf, both divided but differing in the degree of division; just as in Phlox, celandine, and nettle, there was found a single factorial difference; there was intermediacy in the $F_{1}$ generation and a clear $\mathrm{F}_{2}$ segregation on a I:2:I basis, as in Phlox. Gregory's (I9II) results with primroses were similar to CoRRENS's with the nettles; crenate leaves proved simple dominants to the non-crenate.

Viewing the experimental results in the "Star Phloxes" from the standpoint of physiological morphology, can we conceive of the possible chemical processes involved in the formation of the fringed or incised petals of fimbriata and cuspidata? This question is really one with the whole problem of the nature of the gene and the manner by which 


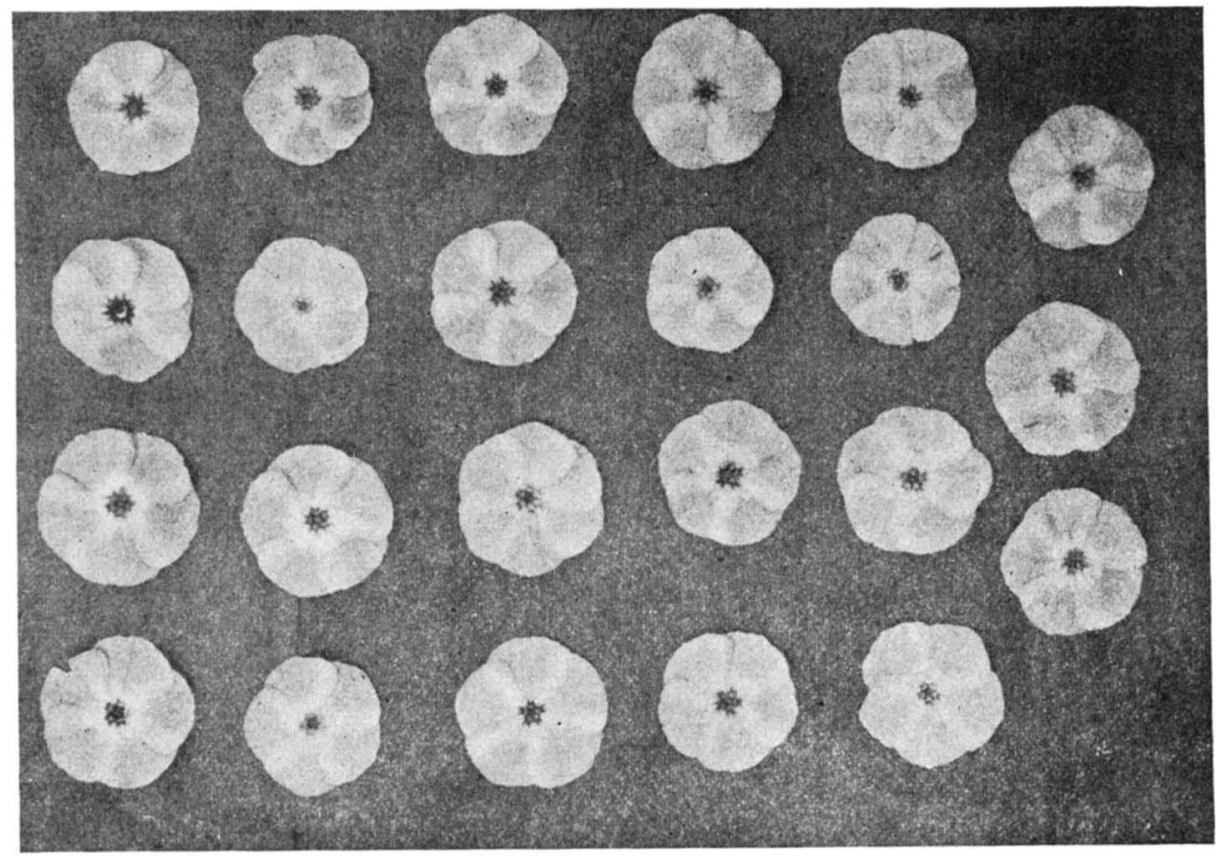

FIGURE 9.-A complete family descended from an entire-flowered segregate.

it achieves somatic expression. JenNings (I9I8), in a survey of recent genetical progress, remarks that the method of action of the genes to produce the later-appearing traits of organisms constitutes a field of research as yet little touched. Some scientists conceive the process to be enzymatic and assert that the genes are enzymes or substances which during ontogeny give rise to enzymes; that these catalyze the formation of substances distinctive chemically, which in turn are thought to form more or less directly structures or organs correspondingly distinctive. This sequence of events is a plausible one for the formation of the entiremargined flowers; it seems that in addition, in the fimbriata and cuspidata types, there is at work an inhibiting substance which retards directly the growth of the epidermal layer and to a less extent and perhaps indirectly the mesodermal layers of the petals, this retardation being less in three regions (leading to the formation of the teeth) which seem to correspond to three chief veins at the very base of the corolla lobes; the veins supply water and may be supposed to dilute the inhibitor in their vicinity, leading to tooth development. What are the reasons for assuming such an inhibitor? As pointed out before, all colored fimbriata and cuspidata 
flowers display a more or less irregular, narrow, colorless margin (figure $10, \mathrm{C})$; this sort of periphery never occurred in any of the entire segregates from fimbriata parents. Microscopic examination of freehand sections of corolla lobes reveals at the periphery an interesting condition. All entire flowers, pure whites as well as colored, have the typical papillated epidermal cells to the very edge of the flower, as shown in $\mathrm{B}$ of figure Io; color where present is confined to the papillated cells, never being found in the interior. In flowers of fimbriata and cuspidata the papillated cells do not reach the edge, as shown in A of

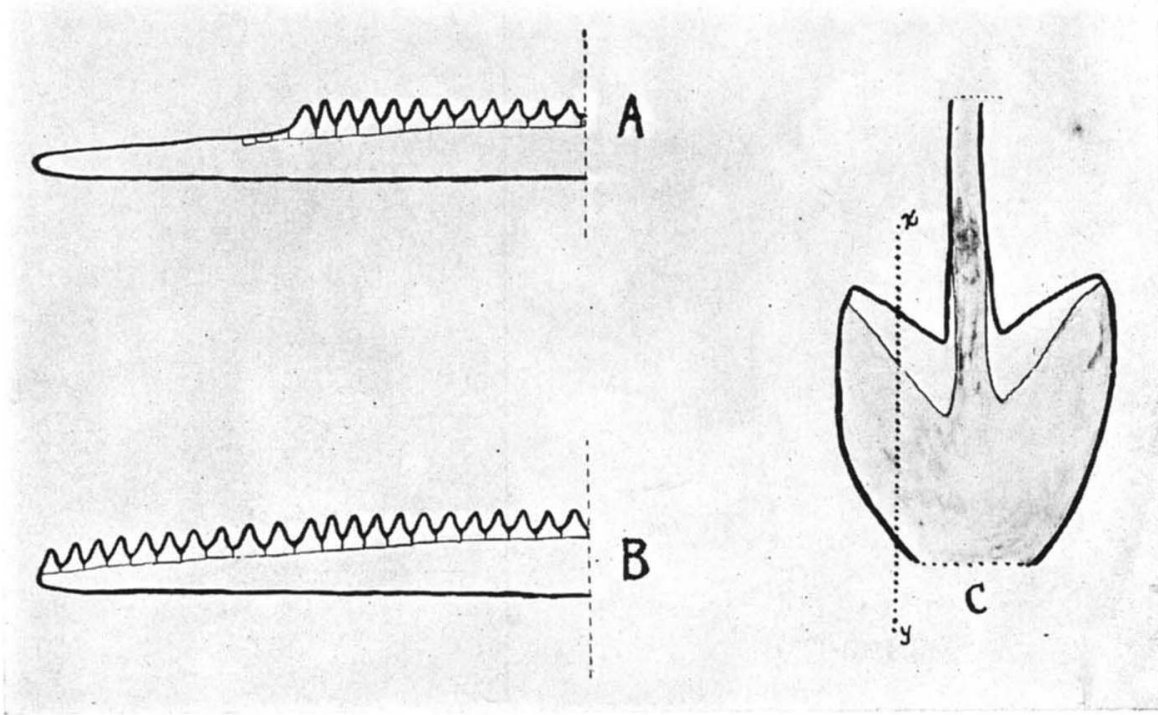

Figure I0.-A is diagram of the peripheral part of section of corolla lobe cut along line $x y$ of $\mathrm{C}$. This represents the condition in fimbriata and cuspidata. B represents a similar section of an entire-edged flower. $C$ is a surface view of a portion of a cuspidata flower. Note the outer white edging of the flower.

figure Io; where the papillae cease, color also ceases and hence the white or whitish border to all the incised flowers. This border would seem to be made up of mesodermal cells that had outstripped their epidermis in growth; color production in these forms is a function of the true papillated epidermis and so does not appear in these (supposedly) uncovered mesodermal cells. The conditions described suggest the presence of a growth-inhibitor in the epidermis, which restricts the size, produces the laciniation, and the white-bordered condition in the fimbriata and cuspidata flowers. 
Shull (I9I2) has called attention to the occasional incompleteness of action of inhibitors; the fluctuational variation of several fimbriata flowers to entire, as already described, might be explained in this way. In our factorial summary we shall designate by $I_{e}$ the factor, which in homozygous condition, causes the cuspidate form; this symbol has reference to the fact that it is apparently an inhibitor (partial) affecting the epidermal development.

\section{The funnel-shaped Phloxes}

My cultures of the funnel-shaped Phloxies were derived from seed designated commercially "Radowitzii." The flowers in full bloom are funnel-shaped; the first ones grown in these cultures possessed a ground

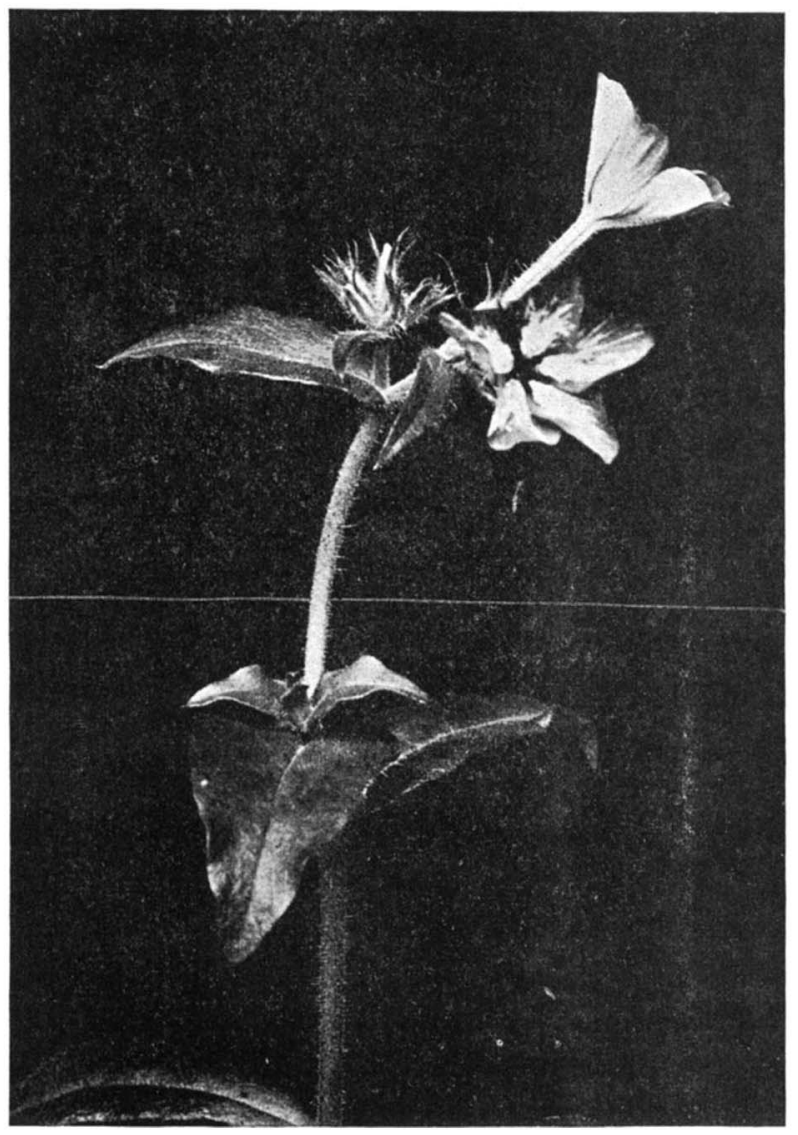

Figure II.-The deep funnel type. A colored plant showing the white streaking always associated with flower color in the funnel-shaped type. 
color of about a "Tyrian pink" which was streaked with white. Figure II shows this type of funnel-shaped Phlox; besides the characteristic shape, this type of flower commonly possesses small, irregularly distributed green streaks, and when these bits of green are at the periphery the latter becomes slightly indented. In the course of hybridization, true-breeding funnel-shaped Phloxes have arisen that are entirely white save for occasional green streakings (KELLY I9I7); figure I2 is from a photograph of some of these. Other colors than "Tyrian pink" have occurred but in every case the white streaking on a colored background accompanies the funnel shape. This shape, then, as far as observations go, occurs independently of color, and always when colored is associated with white streaks on a colored ground.

My records show that selfings of 28 different funnel-shaped plants have been made at various times, giving a total of 357 progeny, and that these were unexceptionally funnel-shaped. In I9I6 one family of 34 plants had its flowers oniy shallowly funnel-shaped; a I9I 7 group descended from one of these shallow-flowered plants, consisted' of 20 sibs that were similarly shallow; the shallow-flowered condition is shown to the left of figure 12, while to the right is shown the commoner deep type of the writer's cultures. The hybridization work to be described was done with the latter sort (designated by an " $\mathrm{I}$ " in the records). All the other varieties of Phlox grown by the author had salver-shaped flowers.

The crossing between the funnel-shaped and the salver-shaped types has been made reciprocally and repeatedly. The results have always been the same; the $F_{1}$ hybrids show always a perfect dominance of the salvershaped character. (Figure $I_{3}$ shows the funnel-shaped and salvershaped types to the left and right respectively, together with their $F_{1}$ hybrid in the centre of the picture.) Seventeen hybridizations have been made between such parents, resulting in $89 F_{1}$ progeny, all salver-shaped. When color was involved in the $F_{1}$ hybrids the white streaking along the center of each corolla lobe proved recessive together with the funnel shape, and the irregularly distributed green streaks were likewise not apparent.

Sixteen of the $F_{1}$ plants were self-pollinated in different seasons, yielding a total of $7 \mathrm{I} 3$ offspring; this $\mathrm{F}_{2}$ generation was composed of plants of two kinds: 534 salver-shaped and I79 funnel-shaped (see table 3). This ratio is a nearly perfect Mendelian one for a single factorial difference (with dominance).

Expectation, on this basis, would call for 534.75 salver-shaped and I78.25 funnel-shaped. 


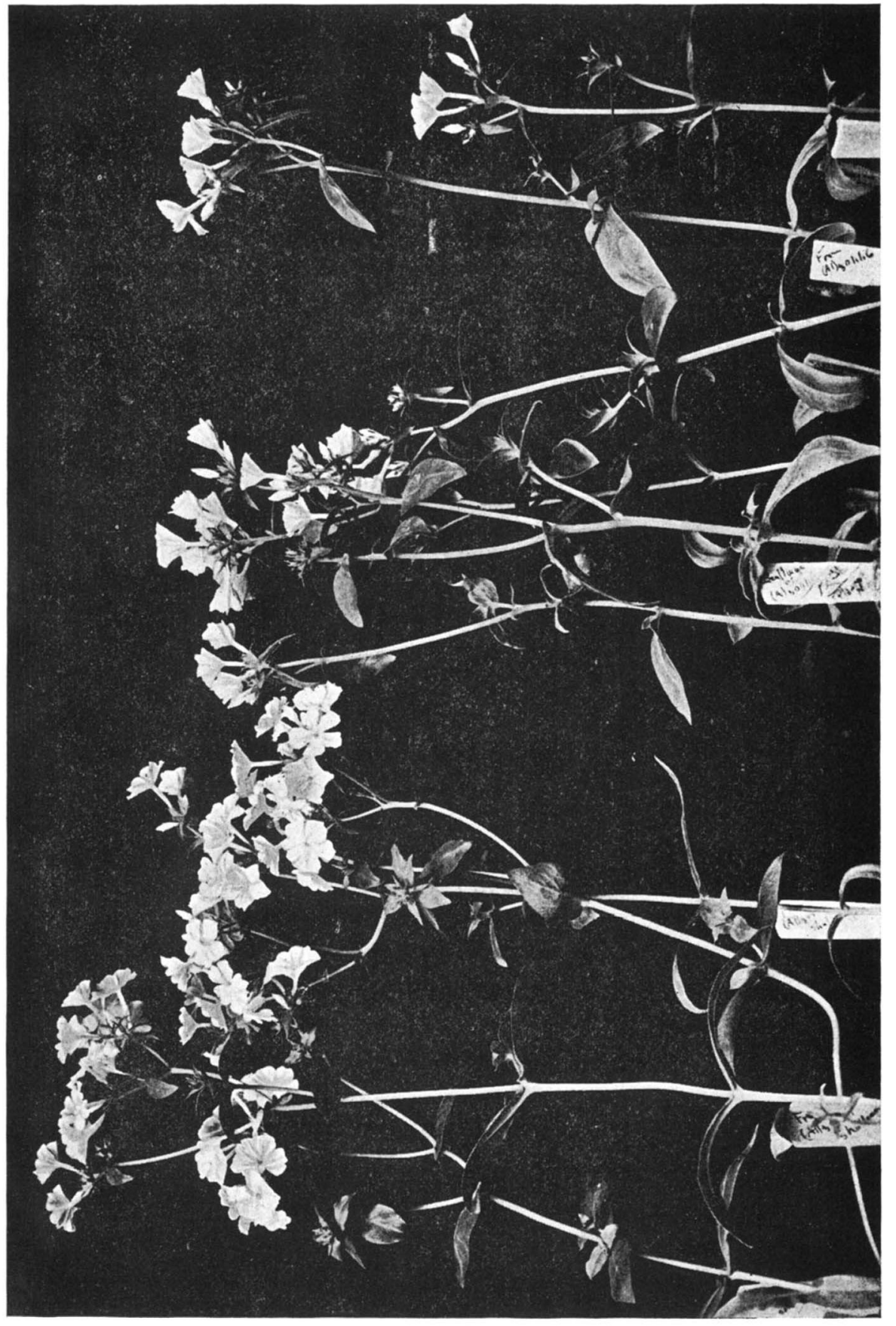

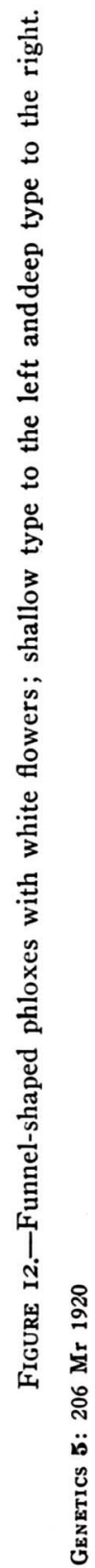


In the factorial summary we shall designate by $S$ the factor which, either in homozygous or heterozygous condition, causes the salver-shaped flower; and by $s$ its allelomorph which, when homozygous, leads to the funnel-shaped condition.

TABLE 3

Composition of the $F_{2}$ generation from crossing of the salver-shaped and funnel-shaped phloxes.

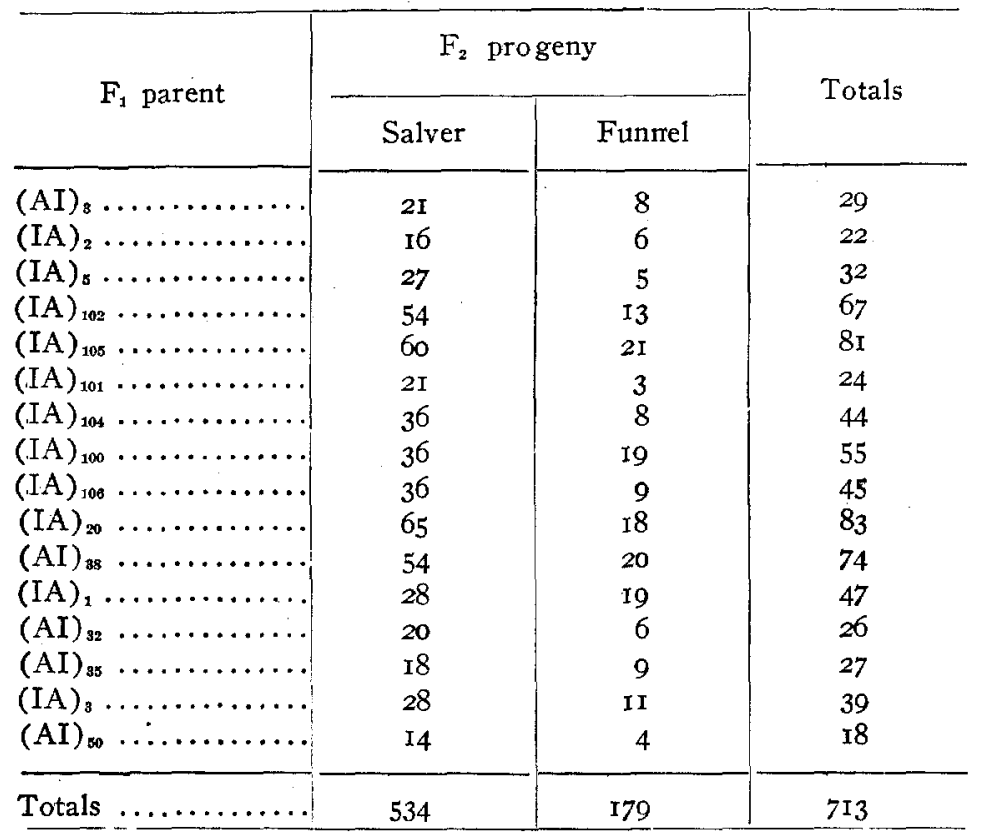

It has been explained already that the funnel character may be shifted about from one color type to another; it has also been evident that this character is independent of flower size, but it would seem that the larger size in funnel-shaped flowers is associated with a shallower condition. Aside from this consideration of size, however, a distinction into deeply and shallowly funnel-shaped is possible (which is genetic) as already pointed out. In the case of one plant, (IA) ${ }_{105 \cdot 1}$, the flowers, even when freshly opened, were nearly salver-shaped, but possessed the occasional green streaking and peripheral notching of petals which is so common a funnel accompaniment; this plant was classified as a funnel with the provision that its final position would rest on the nature of the progeny it produced; these turned out to be undoubted funnels; this case illustrates a decided but non-hereditary variation. Another observation was 
made; flowers on old plants and sometimes old flowers on young plants may become quite salver-shaped. Not all those classed as funnel-shaped, then, possessed the deep funnel shape which characterized the types used in the crossings, but there was ordinarily no trouble in separating the two groups. No attempt was made to subdivide into deeply and shallowly funnel-shaped, but all were counted together in arriving at the figures presented in table 3 .

Fifteen $\mathrm{F}_{3}$ families were grown (table 4), some of which were quite small in number as lack of time prevented the making of a sufficient number of hand-pollinations. Of ten salver-shaped $\mathrm{F}_{2}$ parents tested, 4

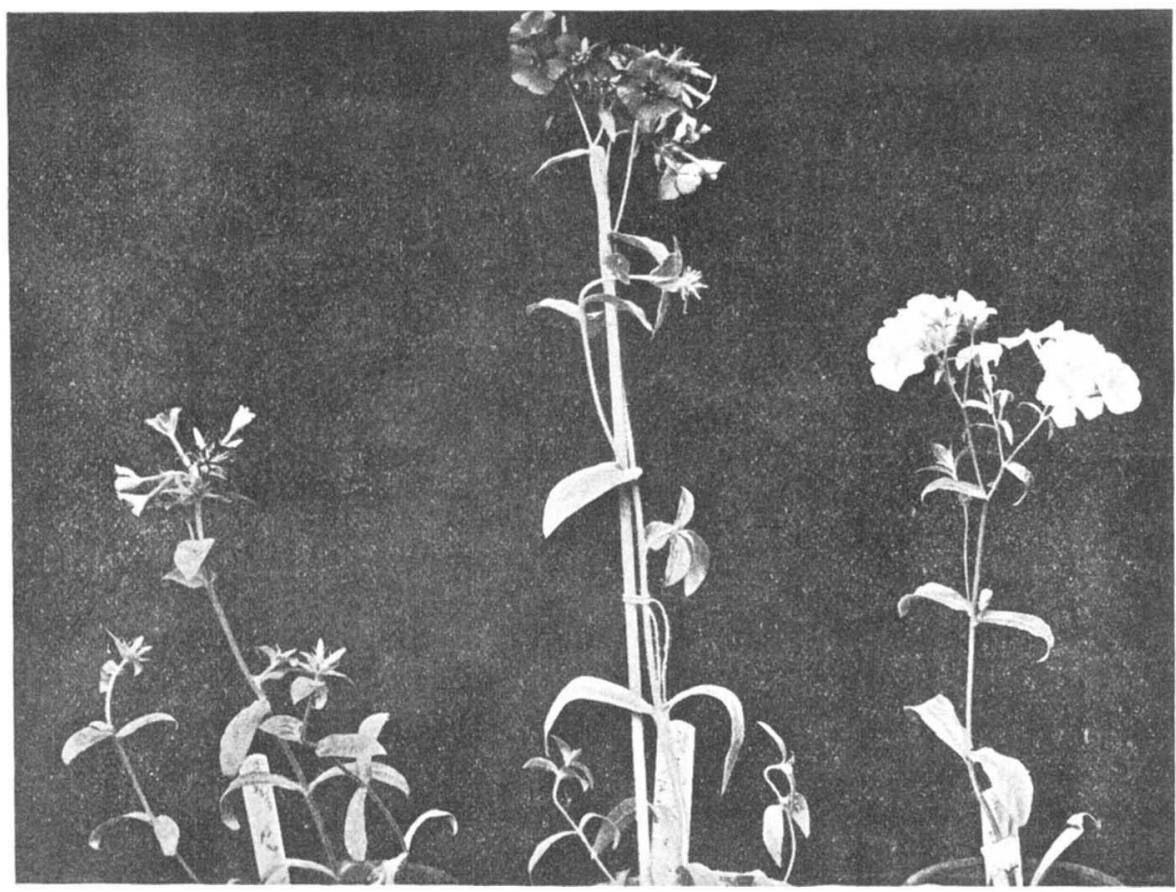

FIGURE I3.-Funnel parent type to the left; salver parent type to the right; in the center, the $F_{1}$ hybrid between them.

gave only salver-shaped offspring and 6 produced a mixture of salvershaped and funnel-shaped. Theory would call for 3.33 of the truebreeding and 6.66 of the heterozygous for every io dominants selected at random from the $F_{2}$ generation. Five funnel-flowered segregates in the $\mathrm{F}_{2}$ generation gave only funnel-flowered progeny in the next generation, in accordance with expectation. 
TABLE 4

Composition of the $F_{3}$ generation from crosses of salver and funnel phloxes.

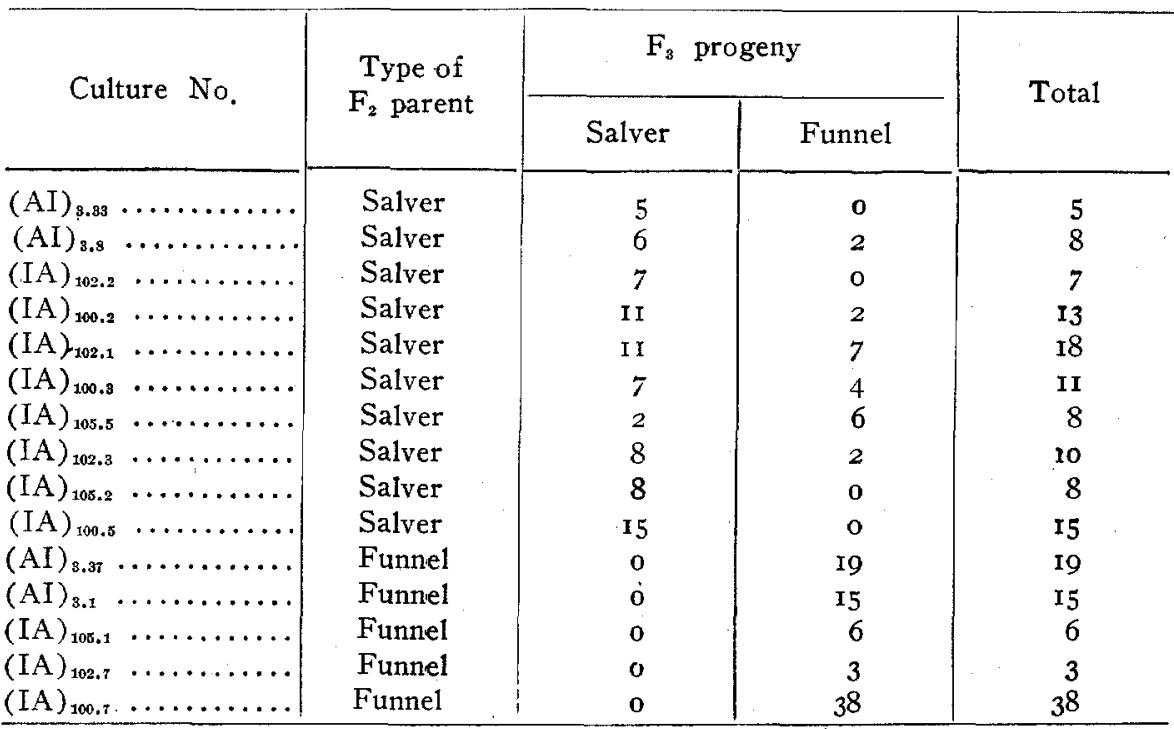

The salver-shaped flower (with blade at right angles to the tube) represents the maximum (as far as observation goes) and also the normal grade of expansion in the species Phlox Drummondii; we have noted two hereditary grades that fall short of the salver condition, i.e., the shallow funnel and the deep funnel shown in figure $\mathbf{I} 2$. The extreme in this direction occurred in a single plant whose flowers did not open at all, the plant being perfectly cleistogamous. No seeds were obtained to test its heredity.

W. T. Thistleton-Dyer (I897) has pointed out that in the cultural evolution of Cyclamen latifolium a form arose whose corolla segments were spreading instead of being typically reflexed; this was a change in the grade of corolla expansion; nothing was reported as to the transmissibility of the new grade.

\section{GENETICS OF FLOWER COLOR}

Factor differences involved when a type with completely white flowers $(A)$ was crossed with a type having dark-eyed white-bladed flowers $(B)$

The $A B$ series

The parental strains have been in pedigree cultures in small numbers from season to season and inbreeding has produced no non-typical speci- 
mens. It should be remarked that not all completely white-flowered strains behave as the one used in the present crossing $\left(A_{51,18.8}\right)$.

There were $19 F_{1}$ hybrids resulting from the cross-pollination of the two parents used, six from the hybridization $A \times B$ and thirteen from the reciprocal $\mathrm{B} \times \mathrm{A}$. The 19 made a decidedly uniform group, bearing flowers whose color was totally unexpected; the color of the blade was a full-colored type, evenly distributed, and corresponded closely with "rhodamine purple" of RIDGWAY's guide; the centre or eye of the flower was a more intense color. This $F_{1}$ group represents a case of complementary factors and the deep color produced resembles somewhat that of the flowers in the colored plate accompanying the original description of Phlox Drummondii by Hooker ( 1835 ); the plants on which HoOKer based his account had been raised from seed imported from Texas, the wild habitat of the species. This $F_{1}$ color is much darker, however, than the color of some Phlox Drummondii which the author grew from seed of wild Texan plants, for which seed the author is indebted to Dr. A. B. Stout of the N. Y. Botanical Garden.

Six of these $F_{1}$ plants were bagged and furnished seed for an $F_{2}$ generation in 1918 , consisting of $3 \mathrm{I} 4$ plants. At first glance the $F_{2}$ aggregation seemed a rather complex mixture of colors with pure white predominant, but a closer scrutiny revealed that nine types comprised the entire family. Eight of the types possessed color of some kind in the flowers and these eight very obviously fell into pairs, one of each pair being "bluer" than its mate.

Types Ia and Ib were both full- or deep-colored with the color uniformly distributed over the blade (flowers with such color distribution are sometimes called "self-colored"); neither possessed a narrow whitish or lighter-colored area immediately surrounding the eye. Ia had a blade color of rhodamine purple, just like the $F_{1}$ hybrid; Ib was the "redder" mate of Ia and had a blade color of Tyrian rose. There were 76 of type Ia and 33 of type Ib.

Types IIa and IIb also possessed a uniform distribution of their blade color (self condition), but this was much paler than in the two preceding types. The color was about "light Phlox purple" in type IIa; in its "redder" mate, IIb, the blade color was about "amaranth pink." Invariably the flowers, at least when young, possess a narrow whitish area immediately outside the eye. It is interesting to note that the IIa blade coloration is like that of the plants grown from wild seed by the writer. There were 26 IIa plants and ${ }_{1} 3$ IIb plants. 
Types IIIa and IIIb differ markedly from the four preceding types in the distribution of the blade color, i.e., the pigment appears to be in minute dots as though stippled on; this stippling is denser near the eye and becomes very sparse near the periphery. The pigment is also deep or full-colored. The author has fallen into the habit of calling the IIIa and IIIb plants "duskies" and uses this name when speaking of them in this paper. The color of the pigmented dots in the "bluer" of the "duskies" is about Rood's violet; in the "redder" of the "duskies" (IIIb) it is about Aster purple or magneta. There were I9 IIIa plants : 8 IIIb plants.

Types IVa and IVb have all color confined to an eye at the center, the blades being clear white (in the present $A B$ series). In type IVa which resembled the " $B$ " grandparent, the eye color is about Rood's violet, while in the "redder" member of this pair of types it is about Aster purple or magenta. There were 7 IVa plants : 2 IVb plants.

The ninth type is designated $\mathrm{V}$ and comprises all plants whose flowers are completely white, thus resembling the "A" grandparent. There was the unexpectedly high number of I 30 plants of type $V$.

Colored plate I rather faithfully reproduces the types, together with the $F_{1}$ and parental types. Table 5 summarizes the $F_{2}$ data.

During the summer of 19 Ig fifty-four $\mathrm{F}_{3}$ families were grown; many. however, were very small in numbers. A survey of the $F_{3}$ families revealed the same striking display of colors, and it was the same nine types in various proportions that made up the individual families. The color distributions are given in detail in table 6 . One somewhat exceptional plant occurred in the progeny of $(A B)_{254.9}$, one of the "duskies" having the stippling dense to the very edge of the flower. The only other aberrant individual among the $889 F_{s}$ plants occurred in the offspring of $(A B)_{251.7}$ where one of the IV group fell in the " $a$ " subgroup when all were expected in IVb.

Certain features in the data of the $F_{2}$ and $F_{3}$ generations, as summarized in tables 5 and 6 , should be emphasized:

a. The occurrence of a series of color types or classes. These have been designated by Roman numerals as already described. I is the darkest (full) self-colored type or class (by "self" is meant that the color is uniform in its distribution over the blade, exclusive of the eye region in this account). II is the paler self-colored type. III is the stippled "dusky" type or class. IV is the type or class with pigment confined to the eye at the center of the flower, the blade being clear white. $V$ is the class with flowers completely white. 
TABLE 5

Flower types in the $F_{2}$ generation of the $A B$ series and thein observed frequencies.

\begin{tabular}{|c|c|c|c|}
\hline $\begin{array}{c}\text { Designation } \\
\text { of } \\
\mathrm{F}_{2} \text { type }\end{array}$ & Color of flower* & & $\begin{array}{c}F_{2} \text { numbers } \\
\text { observed }\end{array}$ \\
\hline Ia $\ldots .$. & Like $F_{1}$ type; blade about rhodamine purple & $\left\{\begin{array}{c}\text { Eye not } \\
\text { whitish bor- }\end{array}\right.$ & 76 \\
\hline $\mathrm{Ib}$ & Tyrian rose flower blade; dark eye & $\left\{\begin{array}{cc}\text { dered } & \text { (see } \\
\text { plate } & \mathrm{I} \text { ) }\end{array}\right.$ & 33 \\
\hline $\mathrm{IIa}$ & $\begin{array}{l}\text { Nearly light Phlox purple; this blade resem- } \\
\text { bles that of wild Phlox as grown by the } \\
\text { writer }\end{array}$ & $\left\{\begin{array}{c}\text { Eye whitish } \\
\text { bordered } \\
\text { (sec }\end{array}\right.$ & 26 \\
\hline $\operatorname{Ilb} \ldots$ & $\begin{array}{l}\text { Blade between deep rose pink and amaranth } \\
\text { pink }\end{array}$ & plate 1) & I3 \\
\hline IIIa & $\begin{array}{l}\text { The "bluer" stippled "dusky"; the color stip- } \\
\text { pled on blade is about Rood's violet }\end{array}$ & & 19 \\
\hline IIIb .. & $\begin{array}{l}\text { The "redder" stippled "dusky"; the color } \\
\text { stippled on blade is about Aster purple or } \\
\text { magenta }\end{array}$ & & 8 \\
\hline IVa & Clear white blade; eye about Rood's violet & & 7 \\
\hline IVb & $\begin{array}{l}\text { Clear white blade; eye about Aster purple or } \\
\text { magenta }\end{array}$ & & 2 \\
\hline \multirow[t]{2}{*}{$V \ldots \ldots \ldots$} & Completely white & & 130 \\
\hline & & Total & 314 \\
\hline
\end{tabular}

* RIDGWAY's "Color standards and color nomenclature" was used in color determination in this work (RIDGWAY 19I2).

b. The very distinct subdivision of each color type into two subtypes marked in the tables and in the colored plate by the small letters "a" and "b". Every "a" group stands out clearly as the blue counterpart of a corresponding " $\mathrm{b}$ " group. This observation obviously points to a "bluing" factor capable of residing and functioning in any class of color. This independent shifting about of a gene is, of course, very characteristic of Mendelian phenomena. The absence of the "blue" factor leads to the "redder" condition.

c. The absence of forms with white eye but colored blade.

d. The theoretically very important facts that not one of the $16 \mathrm{~F}_{2}$ plants of type II produced stippled "dusky" flowers, i.e., flowers of type 
III, among its descendants; that no $F_{2}$ parent of type III on inbreeding produced any plants of type II, types II and III apparently being mutually exclusive; that type I parents are capable of producing both II and III. It would seem, then, (speaking phenotypically) that when type II meets type III it must become something else, indeed, that it must become type I. If type II were independent of type III (say epistatic to it and not affected by its presence) then some of the $\mathrm{I}^{6} \mathrm{~F}_{3}$ families from type II parents should have contained type III plants and some should have lacked them; their total exclusion is significant. These observations receive strong support from the fuller data of the EF series, next to be described. Also to be noted is that type IV gives only IV or $\mathrm{V}$ on inbreeding and that type $V$ produces nothing but type $V$. The following figures from the $F_{2}$ generation are of interest because of their bearing on the number of differential factors in the $\mathrm{AB}$ series concerned with bladecolor formation. First, grouping type II with type I (the latter contains the differential gene for type II) we have $\mathrm{I}_{4} 8 \mathrm{~F}_{2}$ individuals; the total for all the other $F_{2}$ types (not containing the characteristic II gene) is $I 66$; this makes a ratio of $27: 30.2$. Similarly, adding type III and type I (the latter holding the differential factor for type III we obtain I36 $\mathrm{F}_{2}$ plants; all the other $\mathrm{F}_{2}$ plants (not containing the characteristic "dusky" gene) total $\mathrm{I} 78$ individuals; this gives a ratio of $27: 35$.I. The numbers remind one more of a $27: 37$ relationship than of a $9: 7$, suggesting that a triple system of factors is prerequisite for the development of the simpler color types, i.e., types II and III.

e. The large proportion of plants with completely white flower blades, there being $\mathrm{I} 39$ in a total of $3 \mathrm{I}_{4}$ in the $\mathrm{F}_{2}$ generation; that is, there were $\mathrm{I} 75$ with colored blades of all types and $\mathrm{I} 39$ white-bladed ones (some of these white-bladed plants had dark eyes), a ratio of 9:7.15. Roughly, this would indicate that the $F_{1}$ hybrids were heterozygous for two factors for blade color, these factors being so interdependent that absence of either one resulted in complete absence of blade color. Closer consideration of both the $F_{2}$ and $F_{3}$ results reveals a complication, however, which imparts considerabie significance to the plus deviation of 0.15 in the second term of the ratio, giving $9: 7.15$ instead of $9: 7$ which is expected when two complementary factors are concerned. The blade color of type II is in part dependent on a factor that has no part in forming the blade color of type III, as $\mathrm{F}_{3}$ results indicate; and that of type III must be due in part to a specific gene non-existent in type II. These two factors $P$ and $D$, characteristic of types II and III respectively, when 
Types of flower color which appear in the AB series. The completely white-flowered and the dark-eyed white-flowered parents represented at the top (designated by $A$ and $B$ respectively). Immediately below these is shown the type of the $F_{1}$ hybrids. The nine lowermost flowers represent the various types which appear in the $F_{2}$ generation. [The Editor regrets that despite his persistent efforts to secure the whiteness of the flowers of the parental and lower three $F_{2}$ types, the engraver has made them distinctly yellow. The colored types are nearly correct.] 
Kelly, J. P., Flower color in Phlox DRUMmondi

Plate 1

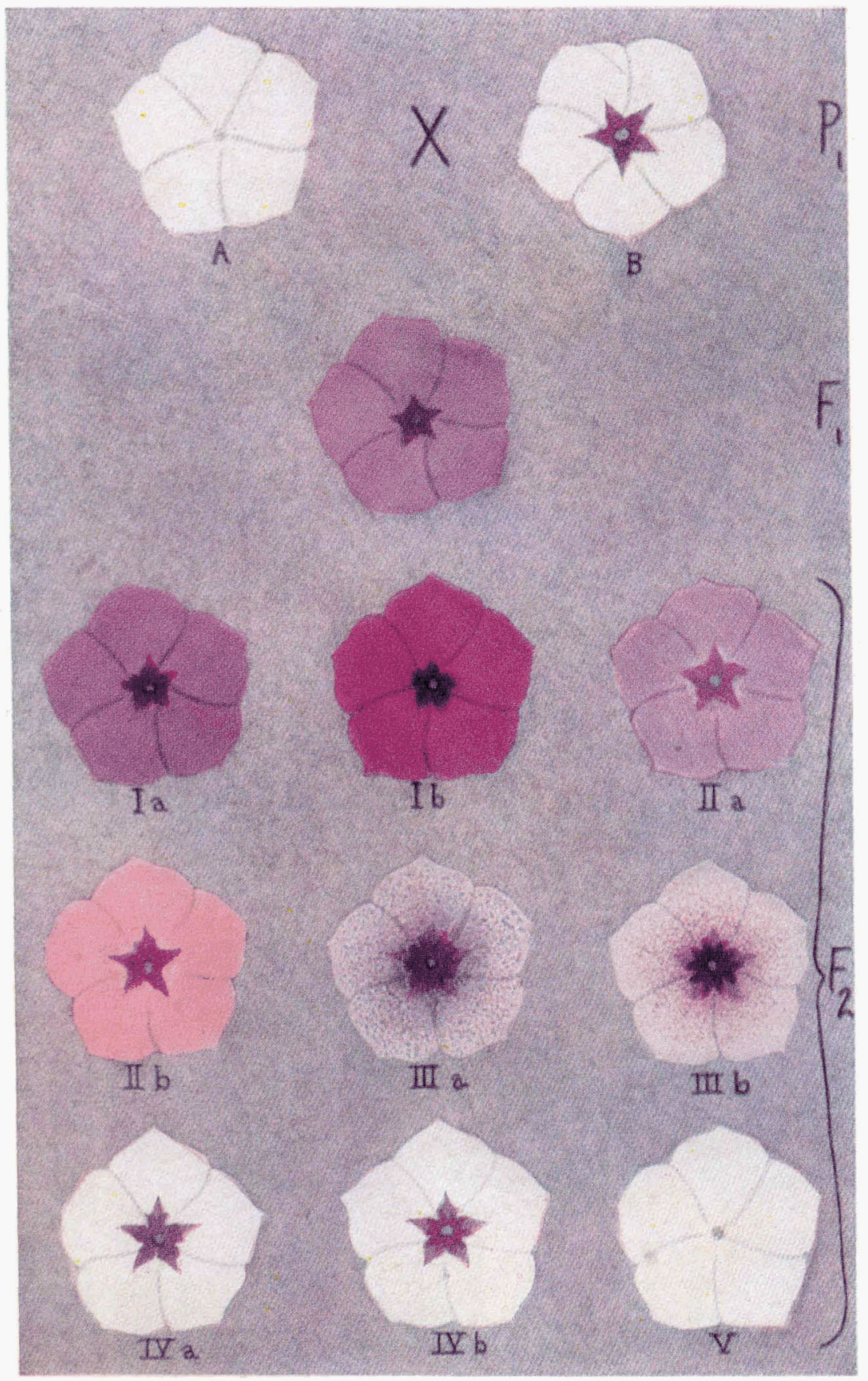

Genetics 5: Mr 1920 
TABLE 6

Composition of the $F_{3}$ generation of the $A B$ series.

\begin{tabular}{|c|c|c|c|c|c|c|c|c|c|c|c|}
\hline \multicolumn{2}{|c|}{$F_{2}$ parent } & \multicolumn{9}{|c|}{$\begin{array}{l}\qquad \mathrm{F}_{2} \text { progeny } \\
\text { Frequencies of the several phenotypes }\end{array}$} & \multirow[t]{2}{*}{ Totals } \\
\hline Designation & Type & Ia & $\mathrm{Ib}$ & $\mathrm{IIa}$ & IIb & IIIa & IIIb & IVa & $\mathrm{IVb}$ & $\mathrm{V}$ & \\
\hline$(A B)_{250.25}$ & Ia & 5 & $\mathbf{I}$ & 2 & - & 3 & - & - & - & 4 & I5 \\
\hline$(B A)_{286.8}$ & Ia & 一 & - & I & 一 & - & 一 & - & - & - & $\mathbf{I}$ \\
\hline$(\mathrm{BA})_{286.1}$ & Ia & 9 & 一 & I & - & 一 & - & - & - & 3 & I3 \\
\hline$(B A)_{268.44}$ & Ia & 14 & 2 & 4 & 2 & 6 & - & I & I & 13 & 43 \\
\hline$(B A)_{260.2}$ & Ia & 6 & 3 & - & - & 一 & - & - & - & 5 & $I_{4}$ \\
\hline$(\mathrm{BA})_{268.28}$ & $\mathrm{Ia}$ & 2 & I & 2 & - & I & - & - & 一 & 3 & 9 \\
\hline$(\mathrm{AB})_{250.2}$ & $\mathrm{Ia}$ & I7 & 2 & 7 & I & - & - & - & - & 4 & $3 \mathrm{I}$ \\
\hline$(\mathrm{AB})_{251.12}$ & Ia & $\mathbf{I}$ & - & 2 & - & - & - & - & - & - & 3 \\
\hline$(\mathrm{AB})_{251.2}$ & $\mathrm{Ia}$ & 6 & 3 & 3 & - & - & - & - & 一 & 5 & 17 \\
\hline$(\mathrm{BA})_{286.35}$ & Ia & 16 & - & 3 & 一 & 2 & 2 & $\mathbf{I}$ & $\mathbf{I}$ & Io & 35 \\
\hline$(\mathrm{BA})_{286.22}$ & Ia & 12 & 3 & 6 & 2 & - & 一 & - & - & 6 & 29 \\
\hline$(A B)_{234.16}$ & Ib & - & 2 & 一 & 一 & 一 & - & - & 一 & - & 2 \\
\hline$(\mathrm{AB})_{250.3}$ & $\mathrm{Ib}$ & - & 3 & - & - & - & 一 & - & - & 3 & 6 \\
\hline$(A B)_{250.1}$ & $\mathrm{Ib}$ & - & 3 & - & $\mathbf{I}$ & - & $\mathbf{I}$ & - & - & 4 & 9 \\
\hline$(\mathrm{BA})_{261.9}$ & $\mathrm{Ib}$ & - & 14 & - & - & - & 7 & - & - & 9 & 30 \\
\hline$(B A)_{286.25}$ & $\mathrm{Ib}$ & - & I & 一 & - & - & - & - & I & - & 2 \\
\hline$(B A)_{206.15}$ & $\mathrm{Ib}$ & - & 5 & - & - & - & - & - & - & I & 6 \\
\hline$(\mathrm{BA})_{286.4 \mathrm{~B}}$ & Ib & - & - & 一 & - & - & 3 & - & - & 2 & 5 \\
\hline$(\mathrm{BA})_{268.7}$ & Ib & - & IO & 一 & - & - & - & - & - & - & ro \\
\hline$(\mathrm{BA})_{261.15}$ & Ib & - & 6 & - & - & - & 5 & - & - & 4 & I5 \\
\hline$(A B)_{250.15}$ & Ib & - & 2 & 一 & - & - & - & - & - & 2 & 4 \\
\hline$(\mathrm{BA})_{268.43}$ & Ib & - & I5 & - & - & - & 5 & - & - & 18 & $3^{8}$ \\
\hline$(\mathrm{BA})_{266.16}$ & $\mathrm{Ib}$ & 一 & I5 & - & - & 一 & 4 & - & - & $\mathrm{I} 2$ & 31 \\
\hline$(\mathrm{BA})_{26 \mathrm{~A} .12}$ & IIa & - & - & Io & 一 & - & - & - & - & 3 & I3 \\
\hline$(\mathrm{BA})_{266,13}$ & IIa & - & - & 4 & - & - & - & - & - & 3 & 7 \\
\hline$(\mathrm{BA})_{266.81}$ & IIa & - & - & 3 & - & - & - & - & - & 4 & 7 \\
\hline$(A B)_{250.5}$ & IIa & - & - & 3 & - & - & 一 & - & - & 2 & 5 \\
\hline$(\mathrm{BA})_{269.6}$ & IIa & - & 一 & I & $\longrightarrow$ & 一 & - & I & - & 3 & 5 \\
\hline$(B A)_{266.21}$ & I.Ia & - & 一 & I & - & - & - & 2 & 一 & 6 & 9 \\
\hline$(A B)_{252.5}$ & IIa & - & - & 7 & 9 & - & - & - & - & I3 & 29 \\
\hline$(\mathrm{BA})_{288.20}$ & IIa & 一 & - & I7 & 8 & - & - & - & - & 8 & 33 \\
\hline$(\mathrm{BA})_{261,3}$ & IIa & - & - & 17 & 2 & - & - & 2 & - & I4 & 35 \\
\hline$(\mathrm{AB})_{251.6}$ & $\mathrm{IIb}$ & - & - & - & I8 & - & - & 一 & 8 & 20 & 46 \\
\hline$(\mathrm{BA})_{260.12}$ & $\mathrm{IIb}$ & - & - & - & $2 \mathrm{I}$ & - & - & - & - & - & $2 \mathbf{I}$ \\
\hline$(A B)_{250.30}$ & IIb & - & - & - & 9 & - & - & - & - & 5 & I4 \\
\hline$(\mathrm{AB})_{251.39}$ & IIb & 一 & - & - & 5 & - & - & - & I & 2 & 8 \\
\hline$(A B)_{251.7}$ & IIb & 一 & - & 一 & 8 & - & - & - & 2 & 8 & I8 \\
\hline$(\mathrm{AB})_{250.20}$ & IIb & - & - & - & 3 & - & - & - & 2 & - & 5 \\
\hline$(\mathrm{AB})_{269.11}$ & IIb & - & - & 一 & 6 & - & - & I & 2 & 9 & 18 \\
\hline
\end{tabular}


TABLE 6 (continued)

\begin{tabular}{|c|c|c|c|c|c|c|c|c|c|c|c|}
\hline \multicolumn{2}{|c|}{$F_{2}$ parent } & \multicolumn{9}{|c|}{$\begin{array}{l}\qquad \mathrm{F}_{3} \text { progeny } \\
\text { Frequencies of the several phenotypes }\end{array}$} & \multirow[t]{2}{*}{ Totals } \\
\hline Designation & Type & $\mathrm{Ta}$ & Ib & IIa & IIb & IIIa & IIIb & IVa & $\mathrm{IVb}$ & $\mathrm{V}$ & \\
\hline$(\mathrm{BA})_{281.2}$ & IIIa & - & - & - & - & $2 \mathrm{I}$ & - & 4 & - & - & 25 \\
\hline$(\mathrm{AB})_{25 t .9}$ & IIIa & - & - & - & - & 3 & - & - & - & 3 & 6 \\
\hline$(A B)_{251.16}$ & IIIa & - & - & - & - & 20 & - & 5 & - & - & 25 \\
\hline$(\mathrm{BA})_{286.11}$ & IIIa & - & - & - & - & 10 & - & - & - & 3 & 13 \\
\hline$(B A)_{280.5}$ & IIIb & - & - & - & - & - & 7 & - & 4 & II & 22 \\
\hline$(\mathrm{AB})_{254.8}$ & IIIb & - & - & - & - & - & - & - & I & 4 & 5 \\
\hline$(B A)_{206.9}$ & IIIb & - & - & - & - & - & 5 & - & - & 4 & 9 \\
\hline$(A B)_{250.8}$ & IIIb & - & - & - & - & - & 7 & - & $\mathbf{I}$ & 4 & 12 \\
\hline$(\mathrm{BA})_{268.10}$ & IIIb & 一 & 一 & - & - & $\longrightarrow$ & II & - & - & Io & $2 \mathrm{I}$ \\
\hline$(A B)_{251.20}$ & IVa & - & - & - & - & - & - & 13 & - & I I & 24 \\
\hline$(\mathrm{BA})_{266.4}$ & IVa & - & - & - & - & - & - & 7 & - & 5 & 12 \\
\hline$(\mathrm{BA})_{286.8}$ & $\mathrm{IVb}$ & - & - & - & - & - & - & - & 12 & 5 & I 7 \\
\hline$(\mathrm{BA})_{286.38}$ & $\mathrm{~V}$ & - & - & - & - & - & - & - & - & 10 & IO \\
\hline$(\mathrm{BA})_{206.6}$ & V & - & - & - & - & - & - & - & - & 16 & 16 \\
\hline$(\mathrm{BA})_{206.5}$ & $\mathrm{~V}$ & - & - & - & - & - & - & - & - & $3^{\mathrm{I}}$ & $3 \pi$ \\
\hline & & & & & & & & & & otal & 889 \\
\hline
\end{tabular}

present together give type I. All blade color, in other words, is here due to the presence (among other things) of either one or both of these two factors specific for II and III, and either or both of these factors will be present in $15 / 16$ ths of the $F_{2}$ zygotes; for rough estimation both may be counted as single homozygous color determiners leaving the number of white-bladed plants to be determined very largely by two other independent genes, $E$ and $A$, which are ineffectual unless both are present. In an exact consideration, of course, it is to be noted that $\mathrm{I} / \mathrm{I} 6$ th of the zygotes will lack the two genes differential for types II and III and this should add slightly to the group of white-bladed individuals, as observation actually showed. Blade color of the simplest sort, then, (that of types II or III) is dependent on three differential factors in the $A B$ series, although the $F_{2}$ figures roughly support a bifactorial difference for the relationship of blade color (all sorts collectively) to lack of blade color.

With the above features of the experiments in mind we find it easy to frame a provisional hypothesis by which to interpret the data. We may 
assume that three distinct factors were essential in the $A B$ series for the appearance of either of the two simple sorts of blade color (types II and III), the absence of even one being sufficient to produce colorlessness in the blade. The most current theory concerning the formation of anthocyanin pigments is based on the work of PALLADIN and of WHELDALE (1916) and applying their conclusions to our factors we may suppose one to be a chromogen-producing factor, $P$ (or $D$ ); the second factor, $E$, may be thought to give rise to an enzyme, possibly of the nature of an oxydase which acts on the chromogen to form anthocayanin color, provided there is present, in turn, a third factor which we may call $A$ and whose function it is to produce an activator for the enzyme; this activator when fully formed might be supposed to have the constitution of an organic peroxide. When all three are present the color produced would be that of type IIb if the chromogen factor present happened to be $P$; if the chromogen factor were $D$ (described below), then the color formed would be the stippled "dusky" type IIIb.

Further, we must obviously assume a factor $B$ whose presence accounts for the "bluer" member of each pair of subtypes. For example in type II, the presence of this factor $B$ would give type IIa, its absence, type IIb. This factor also affects the eye color, as stands out with especial clearness in type IV where no blade color is present.

A factor $D$ that produces the "dusky"-appearing blade color, magenta or Aster purple, is assumed; it is conceived to give rise to an added blade chromogen; it is also conceived to be linked very closely with a factor that causes a stippied distribution of the "dusky" color. A further interesting characteristic imputed to factor $D$ is that it and the factors that produce type II are complementary and give type I; speaking phenotypically we mean to say that II + III $=\mathrm{I}$. More exactly expressed : $D$ and $P$ in the presence of $E$ and $A$ give the type I coloration.

Flowers of Phlox have not been chemically examined to test the assumption that multiple chromogens are present; that it is not unreasonable is attested by WHELDALE's account (1916, page 69) of the pigments in the snapdragon; she found that the crimson and bronze varieties each contained two chromogens (flavones), i.e., apigenin and luteolin.

In Phloxes that bear completely colored flowers the pigment in the outer part of the expanded corolla (the "blade") is distinguishable from that of the central part immediately surrounding the throat (the "eye"). Variation in the species, too, has produced forms with colored blades and colorless eyes; and vice versa. Furthermore, proper crosses show the blade color to be segregable from the eye color. It is plausible 
to suppose that the chromogen bases in the two regions are different and produced by distinct factors. The genes $P$ and $D$, before described, are conceived to be concerned in chromogen production in the outer or blade part of the flower and the factor $M$ is postulated for chromogen production in the eye: Since no colored-bladed white-eyed flowers occurred in this $\mathrm{AB}$ series the $M$ must have been homozygous in these hybrids and contributed by both of the original parents. The factor $M$, in other words, is not differential in the $A B$ series and its somatic expression as the flower eye is not particularly taken into account here; the conditions determining blade color constitute the special interest in this series.

By way of summary, the pertinent factors contained in the two plants originally crossed are listed herewith:

Parent $A_{51.16 .8}$

$P$, chromogen factor for the IIb type of blade color.

$e$, absence or allelomorph of $E$.

$a$, absence or allelomorph of $A$.

$D$, chromogen factor for the IIIb type of color. In the $A B$ and $\mathrm{EF}$ series this color is stippled on.

$b$, absence or allelomorph of $B$. The presence of $b$ in homozygous condition gives the "redder" colorations.

\section{PARENT $\quad \mathrm{B}_{\mathbf{2 1 2 . 5}}$}

$p$, the absence or allelomorph of $P$.

$E$, factor for an enzyme; in presence of factors for a chromogen and activator, $E$ will produce anthocyanin.

$A$, factor for an activator of $E$.

$d$, absence or allelomorph of $D$.

$B$, "bluing" factor.

M, a factor that produces the dark eye is thought to be present in both parents; if it be a chromogen-producing factor it will need the presence of both $E$ and $A$ for expression.

As already explained, when $P$ and $D$ are present together (with $E$ and $A$ ) they interact and give a composite effect (type I).

Five independent pairs of factors are postulated in this scheme. Table 7 lists their possible combinations with the expected numbers for 
TABLE 7

The possible factor combinations for the $F_{2}$ generation of the $A B$ series.

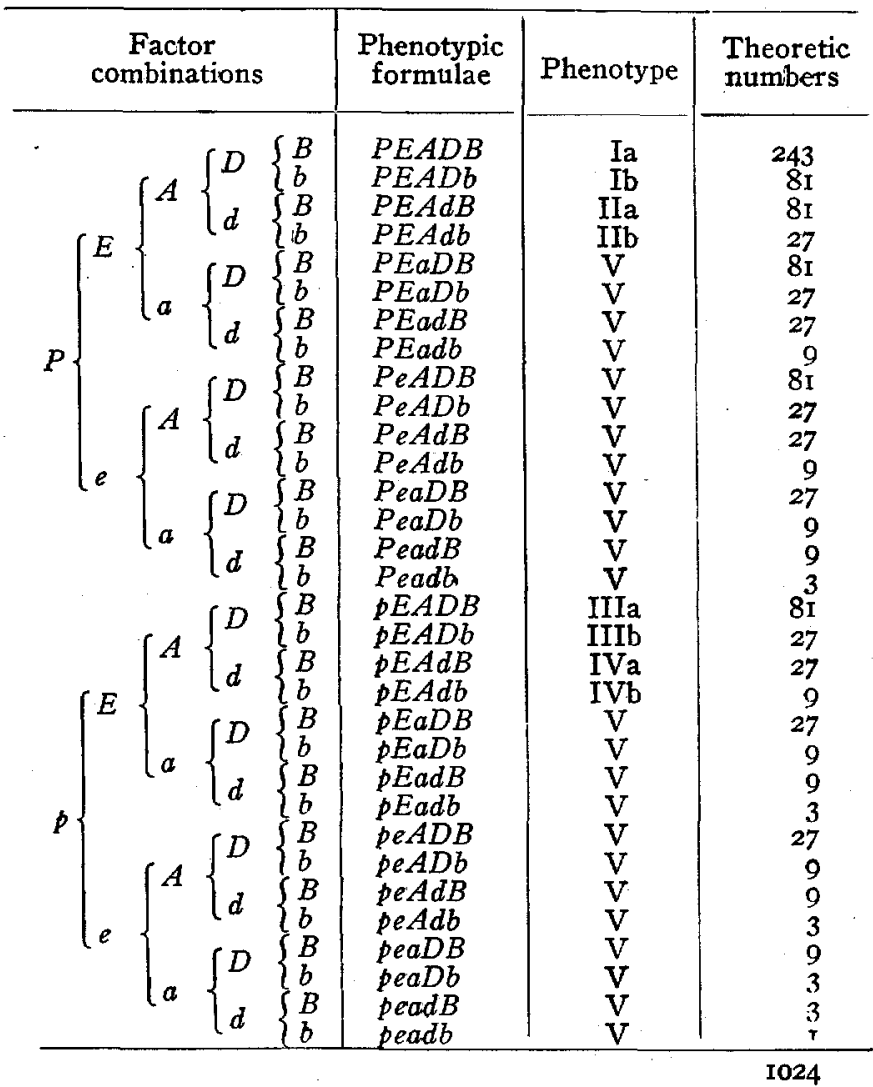

each combination in every $\mathrm{IO}_{24}$ individuals of the $\mathrm{F}_{2}$ generation; the phenotype to which each combination belongs is also indicated. In every I024 individuals then, theory would call for $243 \mathrm{Ia}: 8 \mathrm{I}$ Ib:8I IIa : 27 IIb : 8I IIIa : 27 IIIb : 27 IVa : 9 IVb : $448 \mathrm{~V}$.

Table 8 gives the theoretical expectations based on a total of 314 plants alongside of the observed results. Hypothesis leads us to expect the ratio of the more "bluish" to the more "reddish," i.e., of "a" types to " $b$ " types, to be $3: I$. In the $F_{2}$ generation, however, actual experiments gave

$$
\begin{array}{r}
76 \text { Ia }: 33 \text { Ib; } \\
26 \text { IIa : I3 IIb; } \\
\text { I9 IIIa : } 8 \text { IIIb; } \\
7 \text { IVa : } 2 \text { IVb. }
\end{array}
$$


The ratio of any "a" type to any " $b$ " type averages about $2.3: 1$. There may be some selective elimination affecting the "blue" zygotes; or, the theory of linkage may be invoked to explain this ratio, leading to the adoption of a modified view of the bluing factor. By assuming that instead of a single factor, $B$, conditioning the blue color of the classes, there are two linked genes $B_{1}$ and $B_{2}$, the presence of both of which simultaneously is necessary to give the bluish tint; and by supposing that the linkage value is 90 percent, i.e., that one crossover gamete is formed to every nine non-crossover, there would be then a ratio of "blue" to "red" of 2.3: I. This bifactorial interpretation for the formation of the bluish series has not been experimentally tested, either in the $A B$ series or in the EF series next to be presented; if it be the true explanation crossings of the "red" segregates should recombine $B_{1}$ and $B_{2}$ in some of the hybrids and produce "blues," a result not to be expected on the single-factor hypothesis for bluing. The theoretical numbers in table 8 were based on a single dominant factor for bluing; these calculated numbers and the numbers observed in the experiments are repeated in table I4 (left half), together with the amended theoretical ratios, these last being based on the pair of linked factors for bluing just discussed. The correspondence of observation and calculation is very good. For the nine types observation furnished this ratio,-

$$
76: 33: 26: 13: 19: 8: 7: 2: 130
$$

while theory for the corresponding types gives about,-

$69: 29: 23: 9: 23: 9: 7: 3: 137$. (See table I4 for exact figures.)

For these ratios $\chi^{2}$ is about $4.3 ; n^{\prime}$ is 9 ; and by Elderton's table, $\mathrm{P}$ is .82 .

In postulating a set of five independent genes to account for the genetic behavior described, the question of the number of chromosomes becomes of interest. Sections of the root-tips of seedlings reveals that there are fourteen chromosomes in the somatic cells of Phlox Drummondii.

In connection with the three genes considered prerequisite to any color formation, an attempt was made to describe them in terms of the chemical activities supposed to be associated with them; and the more commonly accepted of the views for the formation of anthocyanin were embodied in that factorial description. Certain investigators, however, notably Combes, Everest, and WillstätTer, start from the same chromogen and arrive at anthocyanin by a different means, i.e., by a reducing 
TABLE 8

Actual and theoretical composition of the $F_{2}$ generation in the $A B$ series.

\begin{tabular}{|c|c|c|}
\hline $\mathrm{F}_{2}$ phenotype & Observation & $\begin{array}{l}\text { Calculation for } \\
\text { 3I4 plants }\end{array}$ \\
\hline Ia........ & 76 & $74.5 \mathrm{I} 35$ \\
\hline Ib.... & 33 & 24.8378 \\
\hline IIa... & 26 & 24.8378 \\
\hline IIb.... & I3 & 8.2792 \\
\hline IIIa... & I9 & 24.8378 \\
\hline IIIb... & 8 & 8.2792 \\
\hline IVa... & 7 & 8.2792 \\
\hline IVb... & 2 & 2.7597 \\
\hline V & I30 & 137.3747 \\
\hline Totals ........ & 3 I4 & 313.9984 \\
\hline
\end{tabular}

For ratios in this table $\chi^{2}$ is $7.6 ; n^{\prime}$ is $9 ; \mathrm{P}$ is 47 .

process. In the case of Phlox Drummondii the author has found that the water extract of white flowers, when treated with nascent hydrogen, becomes pinkish, that is, of a color in quality like that of the anthocyanin in the living flower; oxidative agencies did not achieve this result. No chemical analysis of the artificial pink pigment was made. Some reducing system may perhaps more truly represent the mechanism of color formation. It is known, for example, that methylene blue in milk becomes reduced when a little acetaldehyde is added; this is because of the presence of a reducing enzyme in the milk. To parallel this in the Phloxes we could assume a chromogen that is reduced by a reducing enzyme to an anthocyanin in the presence of some activator like an aldehyde. The substitution of this system for the one already set forth will not alter the nature of the explanation given.

An examination of table 6 shows that among the $F_{3}$ progeny of various $\mathrm{Ib}$ parents there is an unexpected dearth of plants falling in type II; an aberrant number of stippled "duskies" (type III) compared to dark-eyed whites (type IV), however, is just what would be expected on the scheme proposed, It would seem that in these cases, chiefly parents homozygous for stippled "dusky" were inadvertently chosen and the presence of factor $D$ in all gametes would preclude a type II or type IV plant from appearing.

Do the experimental facts of the $F_{3}$ generation as summarized in table 6 bear out the hypothesis that three factors must be present before the production of either of the simpler sorts (II or III) of anthocyanin in the blade takes place? Before considering the details of the table in an 
attempt to answer the question, it should be recalled that there are two triple systems in this $\mathrm{AB}$ series for production of simple blade color. These are distinguished supposedly by the chromogen factor in each. The two systems are

$$
\begin{aligned}
& P+E+A, \text { and } \\
& D+E+A .
\end{aligned}
$$

The $F_{2}$ "duskies" (type III) should give origin to $F_{3}$ families of three kinds, if a triple-factor hypothesis be true, depending on whether the $F_{2}$ parent was heterozygous for one, two, or three of the three requisite factors. With heterozygosity in just one gene there should be about one in four that is non-dusky; with heterozygosity in two of the genes there should be seven out of every sixteen offspring that are non-dusky; where an $\mathrm{F}_{2}$ parent is heterozygous in all three genes there should be 37 non-dusky in every 64 offspring. Similar considerations hold in the case of $F_{2}$ individuals of type II. Type $I$, as has been pointed out, is a composite of II and III. The $F_{3}$ test of the hypothesis of triple systems of complementary genes for the production of the two simple types of blade color is based on a regrouping of the $F_{3}$ data: first, $F_{2}$ plants of types II and III are considered and their progeny are classified into those containing simultaneously $P$ (or $D$ ) $+E+A$, and those not. It should be rèmembered that a stippled "dusky" (III) or a dark-eyed white (IV) lacks the factor $P$ for blade color; plants with completely white flowers lack factor $E$ or $A$ or both. When dealing with the system $P+E+A$, therefore, we mist count stippled "duskies" and dark-eyed whites along with complete whites as being all without the whole set of factors for type II coloration, although another blade color may be present. The data on the groups from $F_{2}$ plants of types III and I bear on the second of the triple systems and the $F_{3}$ progeny are grouped into "dusky" or "dusky"-containing and non-"dusky." Table 9 gives the percentage of plants without $P+E+A$ simultaneously, or without $D+E+A$ simultaneously. The families with less than I 5 members are omitted because of the uncertainty connected with such small numbers.

The data of table 9 are thrown together in a frequency polygon in figure I4. One $\mathrm{F}_{2}$ individual, $(\mathrm{BA})_{268.1}$, must have been homozygous for $P, E$ and $A$, since no whites appeared among its $\mathrm{F}_{3}$ descendants; this individual causes the small peak at o percent. The remainder of the curve shows three maxima; the first somewhere about 25 percent, the second near to 43.75 percent, and the third near $57.8 \mathrm{I}$ percent. This is in accordance with expectation on a three-factor hypothesis; for some 
TABLE 9

Data of the $F_{3}$ generation of the $A B$ series regrouped to show bearing on the hypothesis of multiple factors for the production of coloration of types $I I$ and $I I I$.

\begin{tabular}{|c|c|c|}
\hline \multirow[b]{2}{*}{$\mathrm{F}_{2}$ parent } & \multicolumn{2}{|c|}{$F_{3}$ progeny } \\
\hline & $\begin{array}{l}\text { Percentage } \\
\text { without } \\
P+E+A\end{array}$ & $\begin{array}{c}\text { Percentage } \\
\text { without } \\
D+E+A\end{array}$ \\
\hline 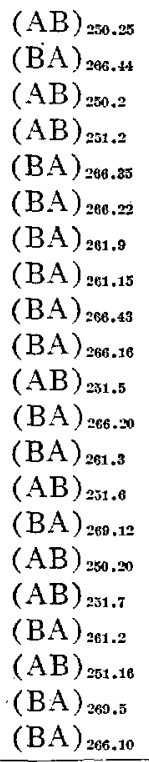 & $\begin{array}{r}46.6 \\
48.8 \\
12.9 \\
29.4 \\
45.7 \\
20.6 \\
53.3 \\
60.0 \\
60.5 \\
51.6 \\
44.8 \\
24.2 \\
45.7 \\
60.8 \\
0.0 \\
55.5 \\
66.6\end{array}$ & $\begin{array}{l}40.0 \\
48.8 \\
38.7 \\
47.0 \\
42.8 \\
48.2 \\
30.0 \\
26.6 \\
47.3 \\
38.7\end{array}$ \\
\hline
\end{tabular}

$F_{2}$ colored individuals should be homozygous for all three essential factors and be incapable of giving white descendants; some should be heterozygous in one of the factors and homozygous in the other two and behave as simple monohybrids, giving rise to 5 percent of white progeny; some should be heterozygous in two factors and homozygous in one, producing an $\mathrm{F}_{2}$ ratio of 9 colored to 7 whites, in other words, give 43.75 percent of whites; the remainder should be heterozygous in all three of the necessary genes and give a ratio of 27 colored to 37 white, which amounts to $57.8 \mathrm{r}$ percent of white offspring.

Our calculations lead us to expect in the $\mathrm{F}_{2}$ generation 27 plants containing genes for a particular blade color in every 64 , on a three factor basis for this blade color; and of these 27 pigmented plants, I should be homozygous for all three genes, 6 should be homozygous for 2 , I 2 should be homozygous for one factor, and 8 should be heterozygous 


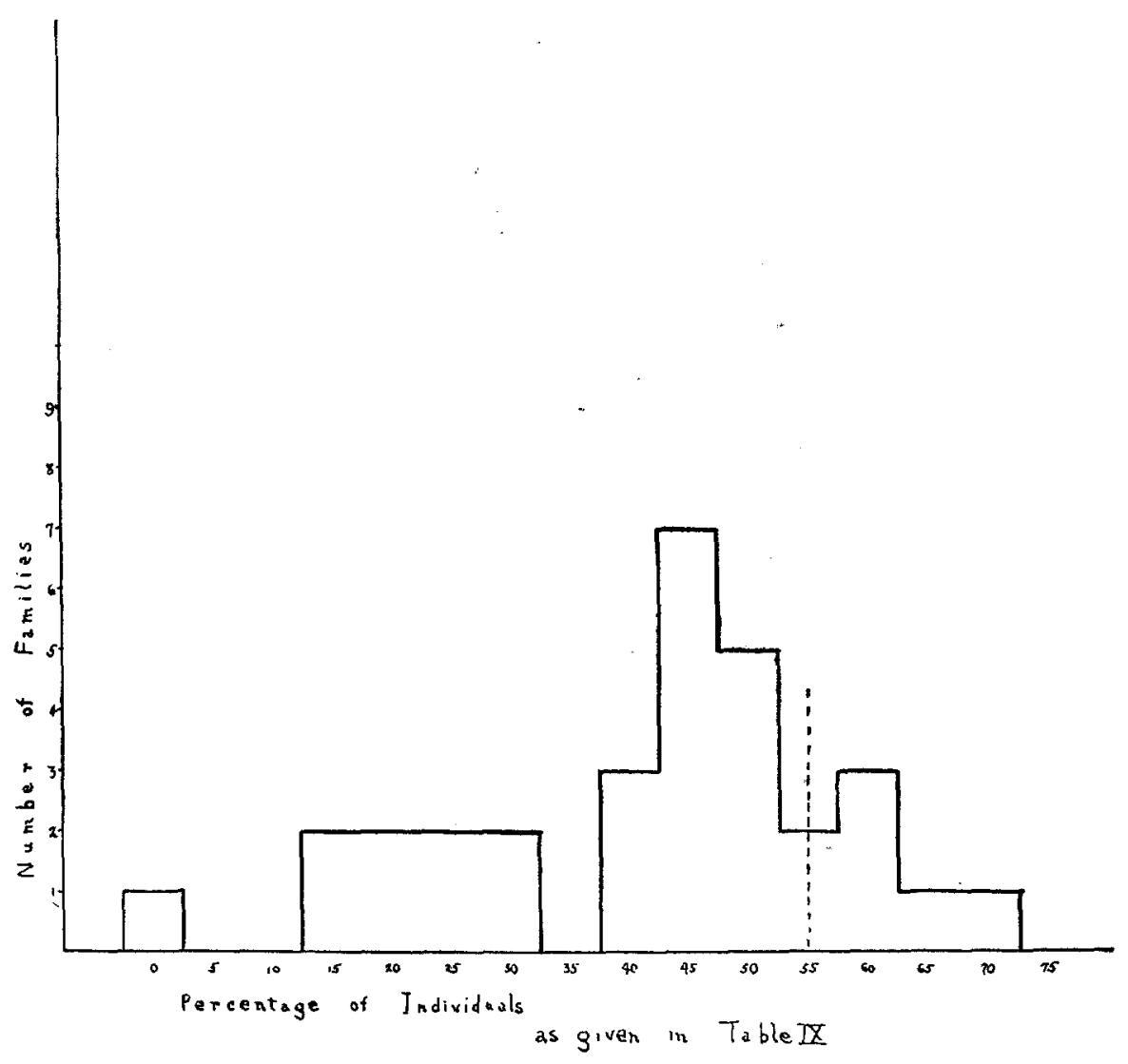

Figure I4-Abscissal numbers show proportion of each $F_{3}$ family not containing simultaneously $P+E+A$ or $D+E+A$. Ordinates give number of families for various abscissal percentages.

for all three. Table 9 and figure 14 give experimental data on the progeny of $3 \mathrm{I}_{2} \mathrm{~F}_{2}$ plants, and for this number theory would call for I.I : $6.8:$ I $3.7: 9$.I plants of the respective genotypic constitutions just enumerated. Our observations gave for these types respectively $I: 8:$ i 6 : 6 , which is a fairly good correspondence with expectation. (The determination of 16 and 6 for the last two classes was obtained by arbitrarily separating the bimodal polygon constituting the right of figure $\mathrm{I}_{4}$ at the 55 percent point.)

\section{Discussion of compound characters}

A brief consideration of "compound characters" (BATESON 1913, p. 60), both where the component elements are capable of independent expression and where they become visible only when present and in- 
teracting, seems desirable at this point. Contributions of EAST (I9I2), EAst and Hayes (I9II), and Emerson (I9I8) have demonstrated that the simultaneous presence of as many as four distinct factors is prerequisite to the formation of aleurone color in maize. These give rise to a reddish pigmentation. The presence of a fifth (dominant) factor causes the production of a bluish coloration.

GREGORY's (I9I I) work on the Chinese primrose (Primula sinensis) reveals an interesting similarity to the $A B$ series just described in the Phloxes; he found that crossing full-colored kinds to a white gave an $\mathrm{F}_{2}$ composed of four types: a, Full-colored selfs; b, paler-colored selfs; c, deep stippled types which he calls "Sirdars"; and d, complete whites. He did not get beyond the $F_{2}$ generation and left undecided the place of the paler selfs in the genetic scheme for the primrose; that is, he could not say whether the paler selfs were an independent series of colors in relation to full-colored selfs or whether they resulted "from the resolution of the combination of factors to which the full color is due." As supporting the latter alternative he pointed out that all the full-colored selfs that were crossed with a white variety called "Snowdrift" gave the paler self-colored types in the $F_{2}$ generation; and that two heterozygous "Sirdars" threw only "Sirdars" and whites. Concerning the "Sirdars," GREGORY considered these to differ from full-colored selfs only by a gene which made for uniform or non-stippled color distribution. There are distinct bluish and reddish subtypes of primroses but unlike the condition in the Phloxes, the "blue" is recessive to "red" and this is the situation also in Lychnis dioica (SHull I912). Data collected through the $\mathrm{F}_{3}$ generation demonstrated the clear interaction-effects between the eye of the flower of primrose and the length of the style; a large diffuse eye acted as an inhibitor to the development of the long style.

The snapdragon (Antirrhinum majus) has been referred to as the most analyzed of plants. BAUR (I9I4) points out the necessity of two factors, $B$ and $F$, for the production of anthocyanin of any kind. In a list of the more important factors of this plant he mentions three, $M$, $M_{1}$ and $L$, that intensify the color produced by $B$ and $F$; he says (page I05) that a plant of the genetic formula $B B F F m m M_{1} M_{1} L L$ and one of the formula $B B F F M M m_{1} m_{1} l l$ are both of about the same color, i.e., a dark flesh color. The combination of the two with formula $B B F F M M M_{1} M_{1} L L$, is a plant that is deep velvety blackish-red ("satt sammetig schwarzrot"). This is analogous to what appears to be the 
case in Phlox Drummondii where the combination in one plant of the factors producing the stippled "dusky" and the paler-colored selfs gives the full-colored selfs. The snapdragons have also a dominant bluing factor as in the phloxes.

In the sweet pea (Lathyrus odoratus) it has been long known that two factors, $C$ and $R$, must be simultaneously present before any sort of anthocyanin can be formed. In addition, genetic grades of color have been described by Bateson and Punnetr (Bateson I9I3). There is the purple picotee or tinged type which differs from the deep purples by a single factor necessary for the full color of the latter. The corresponding pink picotee or tinged differs because of the same factor from the deep pinks. The condition here is not like that in the phloxes where the gene that effects an intensification of the paler self-colored types is capable of visible expression in the absence of the paler colors. The gene in sweet peas responsible for the "bluer" flower colors is a dominant one, as it is in the phloxes.

Stocks ( Matthiola species) have been investigated especially by Saunders (Bateson and Saunders ig02; Bateson, Saunders and PunNetT 1905, 1906, I908). Here also two factors must be present together for any anthocyanin development; a dominant bluing factor, too, is present giving rise to a "blue" and a "red" series of colors; certain light kinds, flesh-colored and lilac-colored, have appeared which are not well known from the standpoint of their relationships to each other and to the other colors. An interesting example of a compound character due to the interaction of several known genes occurs in stocks. The hairy condition is attributed to the factor $H$ for hairs but this never achieves somatic expression unless the factors $C$ (for cream chromogen) and $R$ (for red coloration) are simultaneously present.

Among animals a classical case of a compound character and of spectacular factor interactions is that of the walnut comb in fowls (BATEson, Saunders and Punnetr 1905, ig06; also Bateson 1913). Just as in the phloxes where the resolved components of the full-colored selfs exhibited themselves independently as stippled "dusky" and paler selfcolored types, so here the components of walnut comb, by themselves, attain independent expression in the form of the rose and the pea combs.

It seems needless to cite further cases. The whole trend of recent genetics is to get away from the idea of a gene independently and exclusively conditioning some "unit character" in the soma; and it is likely that factor interaction in a less spectactlar manner than in the cases just discussed must be very common in the living world. 
THE CROSSING OE BRILLIANT "RED" OR CARMINE (E) BY PURE CREAM (F) -THE EF SERIES

The red parent (cultural designation $E_{47,1.1}$ ) and the cream parent $\left(F_{51,2.8}\right)$ were both members of lines that had been the two preceding seasons in pedigree culture and known to be true-breeding for red and cream respectively. According to RIDGway's "Color standards and nomenclature" the cream of the blade was marguerite yellow while the red was difficult to match in that guide but it seemed to be about a brilliant pomegranate purple or carmine.

The $F_{1}$ generation consisted of fifteen plants that made a remarkably uniform group; the outer blade color of the flowers was very close to RIDGWAY's rhodamine purple while the eye region was deeper. The $F_{1}$ color seemed not so intense as that of the carmine (E) parent and it was decidedly "bluish" or purplish, indicating that the cream parent (F) had introduced both a cliluting and a bluing factor.

Several of the $F_{1}$ individuals were selfed and gave seed for an $F_{2}$ generation of $53^{\circ}$ plants, grown in $19 \mathrm{r} 8$. The group as a whole presented a striking variety of colors ranging from some that were deeper than the $F_{1}$ type to those completely white. Closer scrutiny revealed $a r e$ markably close parallelism to the conditions already described in the $A B$ series. A few plants looking just like the carmine parent occurred, and also paler reddish self-colored ones, more reddish stippled duskies, reddish dark-eyed kinds (differing from their $A B$ analogues by usually prossessing a characteristic very light stippling external to the eye). For each of the types in this reddish series a closely corresponding type in a bluish series was present. Again, a large number have flowers entirely without anthocyanin. The older flowers of the "d'uskies," of those with color confined to the eye, and the completely non-anthocyanin forms possessed visibly either cream or white plastids; which of the other types were underlaid with cream and which with white could not be determined, as a rule, by inspection; the cream was so light that the quality of the colors of the selfs was not appreciably affected, if at all.

The visibility of cream in the lighter types was one difference setting off the EF series from the $\mathrm{AB}$ series. Another has also been referred to, namely, the appearance of dark-eyed forms with blades lightly stippled and which were quite distinct from the relatively heavily stippled "duskies"; the light stipples graded over into the dark-eyed forms with perfectly clear blades and the separation of the two was made with considerable difficulty and much doubt. There was also perceptible within 
each main group quite minor sub-groups. When recording the $F_{2}$ generation the two groups of full-colored selfs whose eyes were not whitish- or lightish-bordered ( $\mathrm{Ia}$ and $\mathrm{Ib}$ ) and the groups of the palercolored selfs whose eyes were always whitish- or lightish-bordered (IIa and IIb) were each subdivided into a darker and lighter subdivision; the $F_{3}$ observations made in I9I9 indicate that a subdivision of each of the afore-mentioned groups into a darker, a medium, and a lighter would have been more in accordance with the facts; the darker of these three subdivisions (as it occurs in all of the main groups Ia, Ib, IIa, IIb) is not only darker but also "redder" than the medium and lighter ones, showing that the factor concerned here, $D_{e}$ is a slightly reddening as well as a slightly intensifying gene; the "lighter" subdivision is conceived as due to the minor diluting factor, $D_{i}$, while the medium arises when there is neither $D_{e}$ nor $D_{i}$ present. Lastly, this distinction should be emphasized, that, while the main groups among the $\mathrm{EF}$ and $\mathrm{AB}$ series are similar, in the EF series they are more intense in color. It is thought that the factors determining the color types and their relative distinctions are identical in the two groups but that they play upon a genotypic residuum in the EF series that is different from what it is in the AB series. Expressed in other words, the modifications noted in the EF series are probably due to the occurrence of one or more additional factors which have not yet been investigated.

A summary of the $F_{2}$ observations in the $E F$ series is presented in table Io. No separate colored plate was furnished for the EF series since the $F_{2}$ types that arose so closely paralleled those of the $A B$ series pictured in plate $\mathrm{I}$, and the same designations are used in the EF and $\mathrm{AB}$ series for corresponding types. This statement applies also to the type designations in the tables in these two series.

During the summer of 1919 eighty-one $F_{3}$ families were grown comprising a total of 3333 individuals. The EF plants were more readily self-pollinated than the $A B$ plants, and the families therefore run larger. During 19r9 the greater size of the cultures and a limitation of time prevented the subsequent follow-up examination to include lateblooming members of the families but complete observations on the $F_{2}$ generation the preceding year showed that late blooming is not associated with any particular type of flower; that late-bloomers represent a random sample of the population so far as the characters under investigation are concerned. 
TABLE IO

Flower types in the $F$, generation of theEF series and their observed frequencies.

\begin{tabular}{|c|c|c|c|}
\hline $\begin{array}{l}\text { Designation } \\
\text { of } \mathrm{F}_{2} \text { type }\end{array}$ & \multicolumn{2}{|l|}{ Color of flowers } & $\begin{array}{l}\text { Observed } F_{2} \\
\text { numbers }\end{array}$ \\
\hline $\begin{array}{l}\text { lighter } \\
\text { darker }\end{array}$ & $\begin{array}{l}\text { Like } F_{1} \text { color and those close to it; } \\
\text { blade close to rhodamine purple } \\
\text { Deeper than } F_{1} \text {; blade about a brilliant } \\
\text { Aster purple }\end{array}$ & \multirow{2}{*}{$\begin{array}{l}\text { No } \\
\text { lighter } \\
\text { area } \\
\text { near } \\
\text { border } \\
\text { of } \\
\text { eye }\end{array}$} & $\left.\begin{array}{l}103 \\
28\end{array}\right\} \mathrm{I3I}$ \\
\hline $\begin{array}{l}\text { lighter } \\
\text { darker }\end{array}$ & $\begin{array}{l}\text { Blade about tyrian rose } \\
\text { Blade about bright carmine or bright } \\
\text { pomegranate purple (= E parent } \\
\text { type) }\end{array}$ & & 5762 \\
\hline $\begin{array}{ll} & \text { lighter } \\
\text { IIa } & \\
& \text { darker }\end{array}$ & $\begin{array}{l}\text { Blade from rhodamine purple to true } \\
\text { purple } \\
\text { Blade perhaps between rhodamine pur- } \\
\text { ple and Aster purple }\end{array}$ & $\begin{array}{l}\text { Eye } \\
\text { bordered } \\
\text { by } \\
\text { whitish }\end{array}$ & $\left.\begin{array}{r}59 \\
*_{14}\end{array}\right\} 73$ \\
\hline $\begin{array}{ll}\text { IIb lighter } \\
\\
\text { darker }\end{array}$ & $\begin{array}{l}\text { Blade between tyrian pink and tyrian } \\
\text { rose } \\
\text { Blade very close to tyrian rose }\end{array}$ & $\begin{array}{l}\text { or } \\
\text { lighter } \\
\text { area }\end{array}$ & $\left.{ }_{4}^{24}\right\} 28$ \\
\hline IIIa & $\begin{array}{l}\text { Srippled "dusky"; color about pansy } \\
\text { Rood's violet }\end{array}$ & violet or & 43 \\
\hline IIIb & $\begin{array}{l}\text { Stippled "dusky"; color about Aster p } \\
\text { magenta }\end{array}$ & urple or & 27 \\
\hline IVa ${ }_{\text {clear }}^{\text {stipple }}$ & $\begin{array}{l}\text { Violet-eyed with relatively few stipples } \\
\text { blade } \\
\text { Same as last but with apparently undot } \\
\text { stippled blade }\end{array}$ & or dots on & $\left.{ }_{14}^{14}\right\} 28$ \\
\hline IVb ${ }_{\text {clear }}^{\text {stipple }}$ & $\begin{array}{l}\text { Aster purple or magenta eye and blade } \\
\text { stippling } \\
\text { Same as last but with apparently undot } \\
\text { stippled blade }\end{array}$ & $\begin{array}{l}\text { with sparse } \\
\text { ted or un- }\end{array}$ & $\left.{ }_{\text {II }}^{3}\right\} \mathrm{I} 4$ \\
\hline $\begin{array}{l}\text { white } \\
\text { cream }\end{array}$ & $\begin{array}{l}\text { Blade and eye completely white } \\
\text { Blade and eye completely cream }\end{array}$ & & \}$_{34}^{90)} 124$ \\
\hline & & & Total 530 \\
\hline
\end{tabular}

* Four allotted to this group whose classification was somewhat doubtful. 
A complete summary of the data of the $F_{3}$ families (together with an indication of the types of the $F_{2}$ parents) is given in table $\mathrm{II}$. The following features of the data of the $F_{2}$ and $F_{3}$ generations as summarized in tables Io and I s should be emphasized:

a. A smaller proportion of plants in this series than in the $A B$ series whose flower blades lack anthocyanin, these having blades white or cream, or at most merely lightly stippled with anthocyanin. There were 166 such in 530 , or a ratio of $\mathrm{I}: 2.19$.

b. The occurrence again of a series of types of coloration just as was found in the $A B$ series and in their larger features analogous to those found in that series.

c. The clear division again of each main group into two, a relatively "bluer" denoted by the letter "a" and a relatively "redder" denoted by "b". Certain finer sub-divisions within the groups have already been referred to.

d. As a slight variation on the $A B$ series, this $E F$ series contained many plants of a somewhat distinct type of blade color named by the writer "light stipple". which are not easily confused with the type called stippled "dusky." These "light stipples" appear like ordinary darkeyed whites or creams whose eye color has become lightly scattered out over the blade. The parallelism to the less involved $A B$ series allows the tracing of an analogy (homology is probably the proper word) between these two series. In individual $F_{3}$ families it was perfectly evident that there was the "homologue" of type I, full-colored and eye with no whitish or light area bounding it; there was the homologue of type II, slightly lighter than I but with the eye invariably possessing whitish or lightercolored areas at its edge as in type II of the $A B$ series (see plate I); type III was represented in similar "duskies" that were heavily stippled; and then just where in the AB series we look for clear-bladed dark-eyed forms (type $I V$ ) we find here, as a rule, the lightly stippled form; the parallelism is so close in its many features that the author has not hesitated to group these "light stipples" (which are sharply distinct from the stippled "duskies") with the relatively few clear-bladed darkeyed plants that occurred, as type IV, always stating, however, under IV which were "light stipples" and which were clear-bladed. It would seem, too, that plants passing as clear-bladed may be genotypically "light stipples," as was obviously the case with (EF) ${ }_{255.6}$ (this was parent No. 74 in table I I ) ; its $\mathrm{F}_{3}$ progeny that developed color were nearly all "light stipples." The whole tendency seems to be to substitute the dark-eyed types with lightly stippled blades for the type (dark-eyed and clear-bladed) 
that exclusively characterized the $\mathrm{AB}$ series. It is questionable whether any of the plants classified as "clear-blades" in the EF series are genotypically so; in table I I "light stipples" and "clear blades" were separated as well as mere inspection could do this but they are put together under the general heading IV; together they are considered as equivalent to the group of the same number in table 6 and to the type of the same number pictured in plate $\mathrm{I}$. The belief was expressed above that there must be one or more uninvestigated factors working to shift all the types of blade color in the EF series toward the greater intensity they show as compared to their $\mathrm{AB}$ homologues; it is thought that the same uninvestigated factors also stimulate the clear-bladed forms to the greater degree of coloration evidenced in the light stippling out on the flower blade. The point to be emphasized under " $\mathrm{d}$ " is the apparent replacement of the clear-bladed form by the "light-stipple" form.

e. Considering the slight differences already discussed as unimportant from the present standpoint, table I I is seen to offer a decided confirmation of a feature of table 6 that was important from the theoretical point of view: the paler self-colored types of blade color never throw the (hearily) stippled "dusky" types and the stippled "dusky" parents never produce the paler self-colored types; the full self-colored types (Ia and Ib) give rise to both the paler self-colored (IIa and IIb) and the stippled "duskies" (IIIa and IIIb). The conclusion seems inevitable that (expressed phenotypically)

$$
\text { type II + type III = type } \mathrm{I} \text {. }
$$

The full-colored selfs, then, are simply interaction effects of the palercolored selfs and the "duskies"; or, the paler self-colored and the "duskies" can arise by the genetic resolution of the full-colored selfs.

Leaving out of consideration the factors that modify blade color in a very minor way we can interpret the results of crossing varieties $E$ and $F$ in nearly the same manner as was done for the $A B$ series. The smaller proportion of $F_{2}$ plants without anthocyanin in the blade (or at most in the EF series merely lightly stippled on) indicates that the $F_{1}$ plants were not heterozygous for as many genes prerequisite for anthocyanin formation as in the $\mathrm{AB}$ series. It will be recalled that in the latter series the $F_{2}$ generation showed an apparent rough approximation to a ratio of 9 with blades containing anthocyanin to 7 with blades lacking it. Actually the ratio was 9:7.15 and this on analysis was shown to be due to two sets of triple complementary genes, each complete set by itself making for one of the two simple blade colors. These sets were $E+A+P$ 
and $E+A+D$. In the $\mathrm{EF}$ series the $\mathrm{F}_{2}$ generation reveals a ratio of 3 plants with blades showing marked anthocyanin development to every I.37 lacking this or at most with very light stippling on the blade. This is a rough approximation to a 3 : I ratio pointing to a monomeric difference between blades with anthocyanin and blades without anthocyanin. The plus deviation of the second term of the ratio, however, has a significance here that is similar to that in the $A B$ series. The same genes specific for types II and III are apparently present in the EF series but only one other (whether $E$ or $A$ is purely arbitrary as far as our account goes) was differential and so heterozygous in $F_{1}$. Let us assume that it was gene $E$; then two simple blade color types, II and III, are present here, the former due to factors $E$ and $P$ and the latter dependent on factors $E$ and $D$. All three genes are heterozygous in the $\mathrm{F}_{1}$ generation. In passing to the $\mathrm{F}_{2}$ generation $P$ and $D$, either singly or together, enter I 5/16 of the zygotes and so act approximately like a single homozygous gene for blade color of some sort, leaving the other gene $E$ to produce the approximately $3: 1$ ratio. It can be only approximately because in $1 / 16$ of the zygotes neither $P$ nor $D$ will be present, causing a non-anthocyanous blade even though $E$ be present.

A factor which differentiates a "bluer" and a "redder" subgroup of each class must also be supposed in the EF series.

By way of summary, the following are the more important factor differences assumed:

E PARENT

$b$, absence of bluing factor; gives "red" colors when homozygous.

$P$, same as in the $\mathrm{AB}$ series; gene for chromogen of paler selfcolored type, IIb.

$D$, as in $A B$ series; chromogen factor for "dusky."

$E$, as in $\mathrm{AB}$ series; chromogen factor for enzyme, supposed$1 y$.
F PARENT

$B$, bluing factor.

$p$, allelomorph of $P$.

$d$, allelomorph of $D$.

$e$, allelomorph of $E$.

Table I 2 lists the possible combinations of these factors, the expected numbers for each combination in every 256 individuals, together with the phenotype which each combination produces. Table 13 gives the theoretical expectations recalculated for 530 individuals, and places them beside the observed numbers. 


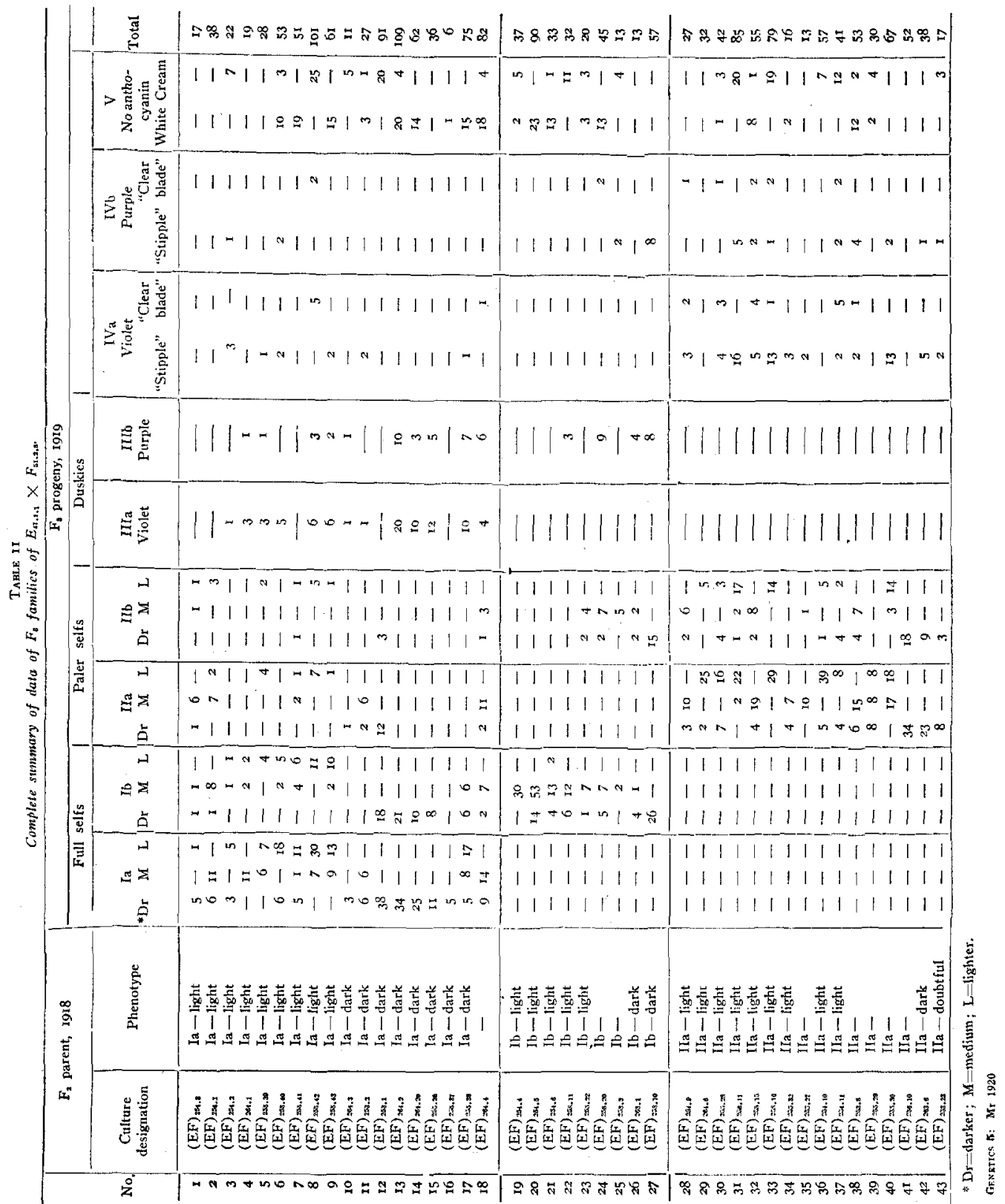




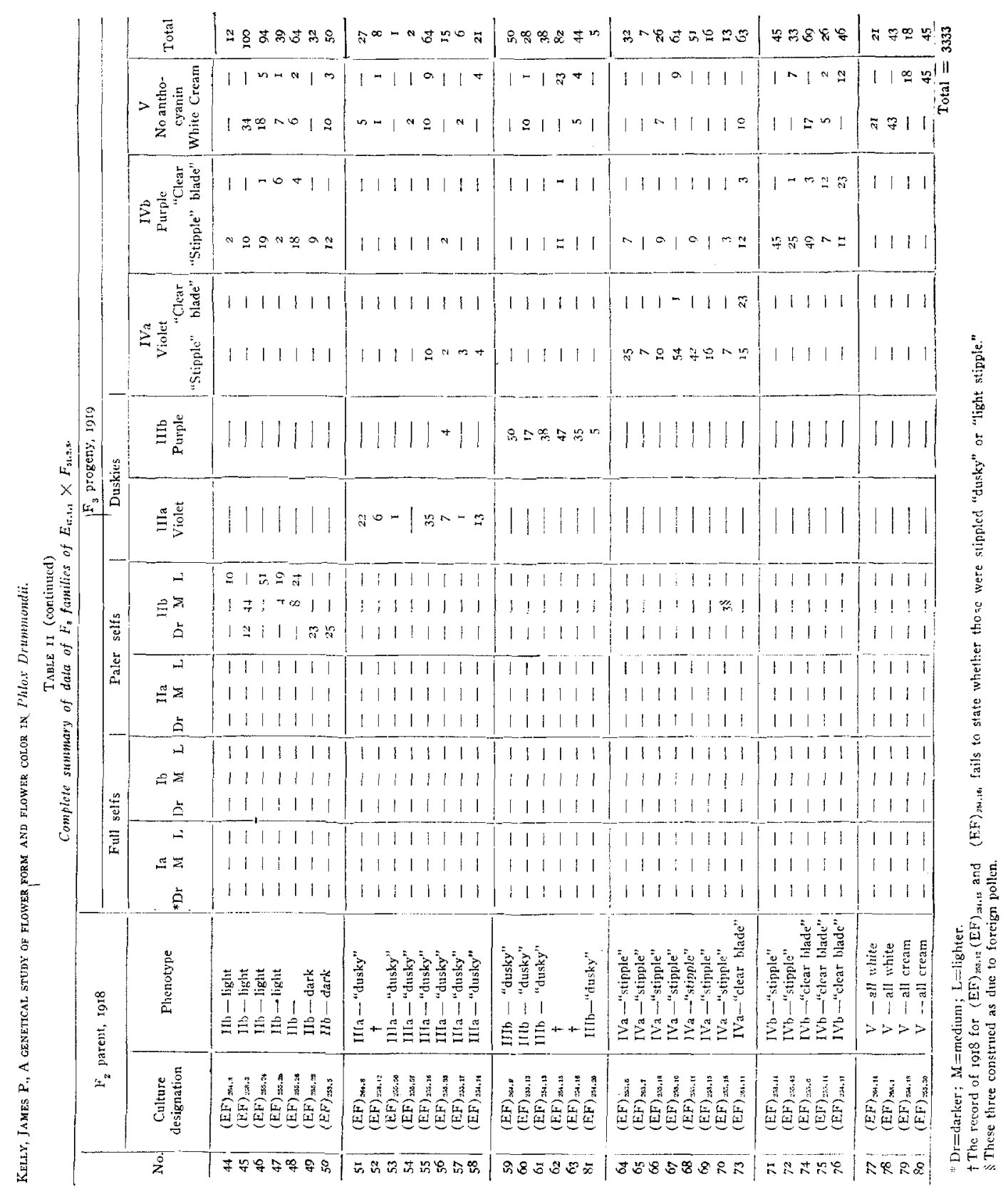


TABLE I2

The possible combinations of the chief factors in the $F_{2}$ generation of the EF series.

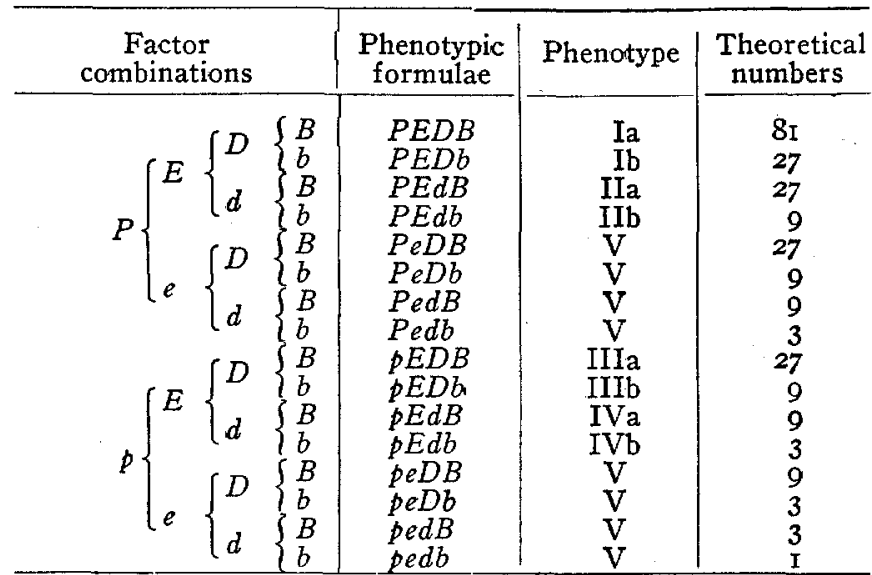

It must be admitted that the calculations in table $\mathrm{I} 3$ show theory and observation to be not exceedingly close fits. In view of the relationship of "dusky" (III), the paler self-colored (II), and the full-colored (I) types, elsewhere emphasized, it is interesting to note that a deficiency of the violet "duskies" (IIIa) is accompanied by a deficiency of the "bluer" full-colored selfs (Ia) but with an excess of the paler "bluish" selfs (IIa); some single cause affecting adversely the appearance of violet dusky gametes would bring about simultaneously the other two deviations from the expected.

TABLE 13

Actual and theoretical composition of the $F_{2}$ generation of the EF series.

\begin{tabular}{c|c|c}
\hline$F_{2}$ phenotype & $\begin{array}{c}\text { Observed } \\
\text { frequencies }\end{array}$ & $\begin{array}{c}\text { Theoretical fre- } \\
\text { quencies for } \\
530 \text { plants }\end{array}$ \\
\hline Ia & I3I & 167.67 \\
Ib & 62 & 55.89 \\
IIa & 73 & 55.89 \\
IIb & 28 & 18.63 \\
IIIa & 43 & 55.89 \\
IIIb & 27 & 18.63 \\
IVa & 28 & 18.63 \\
IVb & I4 & 6.21 \\
V & 124 & I32.48 \\
\hline Total & 530 & 529.92 \\
\hline
\end{tabular}


Let us once more consider the ratio of "blues" to "reds" (i.e., any "a" subgroup to its "b" mate), - - this time in both tables 5 and Io; and of the ratio of "blues" to "reds" among the progeny of heterozygous "a" parents for the main groups of the $F_{3}$ generation of the EF series (as summarized in table II). It becomes evident that the ratio is not $3:$ I as expected on our assumption but averages again about $2.3: \mathrm{I}$. This may be due, as remarked above, to some sort of selective elimination of the "blue" zygotes; but of the "blues" which survive the author cannot assert that they are weaker than the "reds." The theory of linkage has been invoked already to explain this ratio, by assuming that instead of a single factor, $B$, conditioning the "blue" colors of the classes, there are two linked genes, $B_{1}$ and $B_{2}$, the presence of both of which simultaneously is necessary for "blue" formation; and by supposing that the linkage value is 90 percent. The theoretical ratios first proposed for the $A B$ and $E F$ series (see tables 8 and ${ }_{1} 3$ ) were based on a single dominant factor; those calculations and the numbers actually observed in the experiments in both series are repeated in table I4, together with the amended theoretical ratios, these last being based on the pair of factors for "bluing" just discussed. In the EF series the square of chi $\left(x^{2}\right)$ is much reduced by the bifactorial hypothesis for "bluing," but the value of $P$ remains still very small.

TABLE 14

A comparison of two hypotheses concerning the relation of the bluish to the reddish subgroup.

\begin{tabular}{|c|c|c|c|c|c|c|}
\hline \multirow[b]{2}{*}{ Type } & \multicolumn{3}{|c|}{$\mathrm{AB}$ series } & \multicolumn{3}{|c|}{ EF series } \\
\hline & Observation & $\begin{array}{l}\text { Theoretical } \\
\text { I } B \text { gene }\end{array}$ & $\begin{array}{l}\text { Theoretical } \\
2 B \text { genes }\end{array}$ & Observation & $\begin{array}{l}\text { Theoretical } \\
\text { I } B \text { gene }\end{array}$ & $\begin{array}{l}\text { Theoretical } \\
2 B \text { genes }\end{array}$ \\
\hline $\mathrm{Ia}$ & 76 & $74.5 \mathrm{I}$ & 69.54 & r3I & 167.67 & I56.49 \\
\hline $\mathrm{Ib}$ & 33 & 24.83 & 29.80 & 62 & 55.89 & 66.07 \\
\hline $\mathrm{IIa}$ & 26 & 24.83 & 23.18 & 73 & 55.89 & 52.16 \\
\hline $\mathrm{IIb}$ & I3 & 8.27 & 9.93 & 28 & 18.63 & 22.36 \\
\hline IIIa & I9 & 24.83 & 23.18 & 43 & 55.89 & 52.16 \\
\hline IIIb & 8 & 8.27 & 9.93 & 27 & 18.63 & 22.36 \\
\hline IVa & 7 & 8.27 & 7.73 & 28 & 18.63 & $17.3^{8}$ \\
\hline $\mathrm{IVb}$ & 2 & 2.75 & $3.3 \mathrm{I}$ & I4 & 6.21 & 7.46 \\
\hline \multirow[t]{2}{*}{ V } & r 30 & 137.37 & 137.37 & I 24 & $\mathrm{I} 32.48$ & 132.48 \\
\hline & 314 & $\begin{array}{l}x^{2}=7.6 \\
\stackrel{P}{P}=.47\end{array}$ & $\begin{array}{l}\chi^{2}=4.3 \\
\stackrel{P}{P}=.82\end{array}$ & 530 & $\begin{array}{c}x^{2}=40 \\
\text { Pless than } \\
\text {.OI }\end{array}$ & $\begin{array}{c}\chi^{2}=29 \\
\text { also very } \\
\text { small }\end{array}$ \\
\hline
\end{tabular}


At the present stage of investigation it is not meant to urge this bifactorial hypothesis for bluing; it is offered simply as a suggestion. The obtaining of "blues" from matings of extracted "reds". would offer substantiation of the hypothesis, as already pointed out; there should be corroboration also in those $\mathrm{F}_{3}$ families descended from heterozygous $\left(F_{2}\right)$ parents of the Ia, IIa, IIIa, and IVa groups; some of these parents (about one in every eleven) should be heterozygous in just one of the pair of linked bluing factors due to their holding one crossover and one non-crossover chromosome, and such should furnish about 25 percent of "red" progeny; those heterozygous for the two should give 29 or 30 percent of "reds." The percentage of "reds" in the $F_{3}$ families of the large EF series has been calculated and the data form the frequency polygon shown in figure $I_{5}$ (families comprising less than $x_{5}$ colored individuals are omitted). There is some evidence of a peak at about

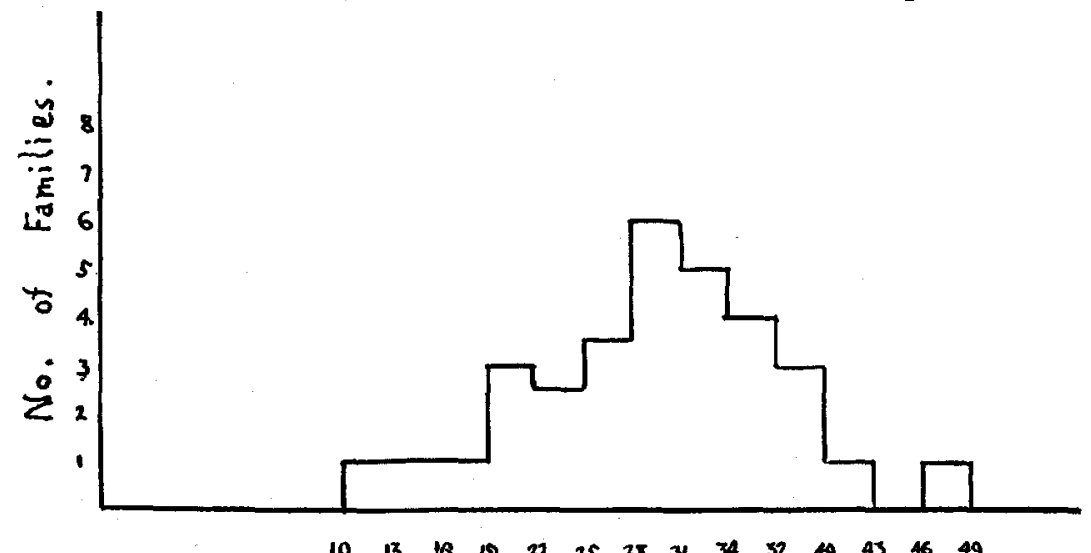

FIGURE 15.-Abscissal numbers show proportion in percent of each $F_{3}$ family that is reddish; ordinates give number of families for various abscissal values.

2 I percent (expected 25 . percent); the high peak at about 29 percent is as expected. Further experimental data are needed to settle the matter.

THE CROSSING OF WHITE-EYED PINK ( $J$ ) AND COMPLETELY WHITE (A)THE JA SERIES

The J parent was one of 26 sibs resulting from the guarded pollination of a plant of commercial origin; all 26 were similar to one another. Each flower had a white eye as a center, surrounded on the outer blade by a color that was close to the eosin pink of RiDGway's guide. The white parent was one of a line that had been observed in pedigree culture for two seasons and had been found to be giving only whites. 
The particular pair of plants used as parents were crossed reciprocally giving five similar offspring; the color of the flower of these $F_{1}$ hybrids was a complete surprise; they were dark-eyed and the outer blade was one of the full colors, tyrian rose. Three of the plants furnished seed for an $F_{2}$ generation of $2 \mathrm{r} 7$ plants. Nine types of flower actually occurred among the descendants of the hybrids of $J$ and $A$, but only eight of these were recorded as occurring in the $\mathrm{F}_{2}$ generation. Plate 2 shows in

TABLE I5

Flower type in the $F_{2}$ generation of the $J A$ series zerith their abserved and calculated frequencies.

\begin{tabular}{|c|c|c|c|}
\hline Type & Color of type & $\begin{array}{l}\text { Observed } \\
\text { numbers } \\
\text { in } F_{2}\end{array}$ & $\begin{array}{l}\text { Theoretical } \\
\text { numbers } \\
\text { for } F_{2}\end{array}$ \\
\hline Ia & $\begin{array}{l}\text { Dark-eyed; blade tyrian rose or bright pome- } \\
\text { granate purple; like } F_{1}\end{array}$ & 64 & 68.6 \\
\hline $\mathrm{Ib}$ & $\begin{array}{l}\text { White-eyed; blade between tyrian rose and } \\
\text { tyrian pink }\end{array}$ & 20 & 22.8 \\
\hline II a & $\begin{array}{l}\text { Dark-eyed; blade like next type (IIb) but } \\
\text { a trifle darker }\end{array}$ & 34 & 22.8 \\
\hline IIb & $\begin{array}{l}\text { White-eyed; blade about eosin pink; like } \\
\text { J parent }\end{array}$ & 13 & 7.6 \\
\hline IIIa & $\begin{array}{l}\text { Dark-eyed; blade about Aster purple or } \\
\text { magenta (= non-stippled "dusky") }\end{array}$ & 23 & 22.8 \\
\hline $\mathrm{IIIb}$ & $\begin{array}{l}\text { White-eyed; blade near mallow pink and } \\
\text { stippled }\end{array}$ & 9 & 7.6 \\
\hline IV & Completely white; like A parent & 48 & 54.2 \\
\hline $\mathrm{Va}$ & Dark-eyed; blade about deep rose pink & 6 & 7.6 \\
\hline \multirow[t]{2}{*}{$\mathrm{Vb}$} & $\begin{array}{l}\text { White-eyed; color usually confined to small } \\
\text { single arrow-shaped spot on each corolla } \\
\text { lobe }\end{array}$ & o & 2.5 \\
\hline & Total & 217 & 216.5 \\
\hline
\end{tabular}

Nore.-In tables $\mathrm{I}_{5}$ and $\mathrm{I} 6$ the distinction between any "a" group and its corresponding " $\mathrm{b}$ " group is not as in the $\mathrm{EF}$ and $\mathrm{A} B$ series, a matter of a bluing factor; in the JA series any "a" group is distinguished from its " $b$ " by a factor for dark-eye; this point will be presently discussed. By ELDERTon's tables, $P$ for the data above is about .Io. 
colors the types of the parents, of the $F_{1}$ generation and of the $F_{2}$ generation; Type $\mathrm{Vb}$, not reported among the $F_{2}$ experimental results, is pictured among the colored $F_{2}$ types, since it is believed that because of the exceedingly small amount of color, even when well developed, and of the fluctuability of what little there is (potentially), that $\mathrm{Vb}$ may have occurred and was counted among the completely white; by the hypothesis to be developed, however, it is expected in only .8 of one percent of the cases and it may not have occurred at all because of the small number of experimental plants, 2I7. Table I 5 summarizes all of the $F_{2}$ data.

Within the more deeply colored of the groups some quite minor variations in the depth of pigmentation were in evidence; these were not selected as the basis for further division, since $F_{3}$ results showed that they continued of minor importance. The types as given in table 15 were sharply distinct except sometimes in the following cases: light forms of type IIa very much resembled Va plants; a slight bluish tinge in the latter which increased with the aging of the flowers would usually separate doubtful cases, but even this did not prevent one obvious misclassification: ( JA) 11.91 $_{1.91}$ was given as $\mathrm{Va}$ in 1918 but by progeny test in 1919 it was shown to have been a lighter IIa plant. In type Vb color is confined as a rule to a single small arrow-shaped spot on each lobe (see plate 2); the color is light and often barely perceptible when it may be easily overlooked and the flower rated as completely white.

During the summer of 1919 thirty-two $F_{3}$ families were grown, comprising a total of $\mathrm{I}_{5} \mathrm{I} 8$ individuals. Table $\mathrm{I} 6$ presents a summary of data, giving to the left the phenotype of the $\mathrm{F}_{2}$ parent and in the body of the table the character of the $\left(\mathrm{F}_{3}\right)$ offspring.

The following points of $F_{2}$ and $F_{3}$ generations (as summarized in tables I5 and I6) should be emphasized:

a. The white-eyed condition was recessive in the $F_{1}$ generation and reappeared in about one-fourth of the $F_{2}$ progeny; the white-eyed $F_{2}$ plants gave only white-eyed offspring in the $F_{3}$ generation.

b. The lightest-colored types, $\mathrm{Va}$ and. $\mathrm{Vb}$, constitute a minor system of colors independent of the rest of the color system, and present in cryptomeric condition probably with all the other colors; at least, one of the factors for the formation of this pale color appears so. Types Va and $\mathrm{Vb}$ are hypostatic to all the other color types and it is possible for all of them to throw $\mathrm{Va}$ and $\mathrm{Vb}$, as shown in the $\mathrm{F}_{3}$ results.

c. Unexpected and especially noteworthy is the fact that the main types, I, II, and III, apparently hold to each other the same relationship as do 
LEGEND FOR PLATE 2

Types of flower color appearing in the JA series. Designated by $J$ and $A$ at the top are the parents that were crossed. Immediately below $J$ and $A$ is shown their $F_{1}$ hybrid; and below the latter the color types appearing in the $F_{2}$ and $F_{3}$ generations. 
Kelly, J. P., Flower color in Phlox Drummondi

Plate 2

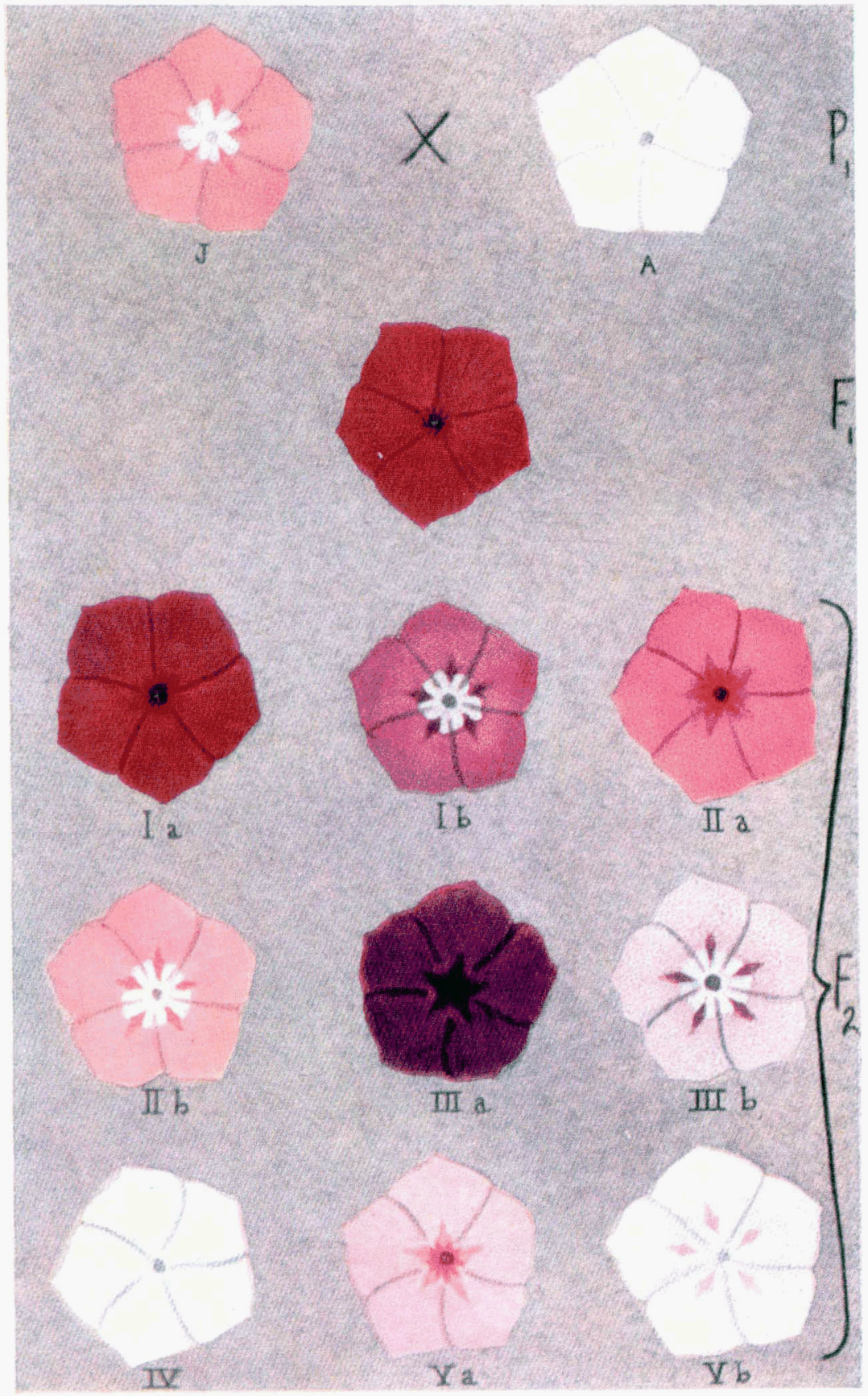


the correspondingly designated types of the $A B$ series and $E F$ series. This means that the non-stippled (self-) magenta or Aster purple type,

TABLE I6

Complete summary of data of $F_{3}$ families in the $J A$ series.

\begin{tabular}{|c|c|c|c|c|c|c|c|c|c|c|c|c|}
\hline \multicolumn{3}{|c|}{$F_{2}$ parent, I9I 8} & \multicolumn{9}{|c|}{$F_{3}$ progeny, IgI9 } & \multirow[b]{2}{*}{ Totals } \\
\hline No. & $\begin{array}{c}\text { Culture } \\
\text { designation }\end{array}$ & $\begin{array}{c}\text { Pheno- } \\
\text { type }\end{array}$ & Ia & $\mathrm{Ib}$ & $\mathrm{IIa}$ & $\mathrm{II} \mathrm{b}$ & IIIa & IIIb & IV & $\mathrm{Va}$ & $\mathrm{Vb}$ & \\
\hline I & $(\mathrm{JA})_{11.62}$ & $\mathrm{Ia}$ & 19 & 7 & 10 & 4 & 8 & 2 & - & $I$ & I & $5^{2}$ \\
\hline 2 & $(\mathrm{JA})_{12.24}$ & Ia & 42 & - & I I & - & II & -1 & 16 & - & - & 80 \\
\hline 3 & $(\mathrm{JA})_{11.73}$ & Ia & 32 & - & 12 & - & 16 & - & - & - & - & 60 \\
\hline 4 & $(\mathrm{JA})_{11.8}$ & Ia & 23 & I5 & 9 & 3 & 7 & 4 & - & - & I & 62 \\
\hline 5 & $(\mathrm{JA})_{12,64}$ & Ia & 48 & - & - & - & 18 & - & I8 & - & - & 84 \\
\hline 6 & $(\mathrm{JA})_{12.72}$ & Ia & $4 \mathrm{I}$ & I8 & 8 & 3 & 18 & 5 & - & 3 & 3 & 99 \\
\hline 7 & $(\mathrm{JA})_{11,22}$ & $\mathrm{Ib}$ & - & 48 & 一 & 8 & - & - & - & - & - & 56 \\
\hline 8 & $(\mathrm{AJ})_{102.3}$ & $\mathrm{Ib}$ & - & 33 & - & 4 & - & 7 & 12 & - & I & 57 \\
\hline 9 & $(J A)_{11.38}$ & $\mathrm{Ib}$ & - & 22 & - & - & - & 7 & 9 & - & I & 39 \\
\hline Io & $(\mathrm{JA})_{11.15}$ & Ib & - & 15 & - & 8 & - & 6 & 20 & - & 2. & $5 \mathrm{I}$ \\
\hline 11 & $(\mathrm{JA})_{11.5}$ & IIa & - & - & 4 & $I$ & - & - & 6 & - & - & II \\
\hline 12 & $(\mathrm{JA})_{11,1 \mathrm{~A}}$ & IIa & - & - & 22 & II & - & - & - & - & - & 33 \\
\hline $\mathbf{I} 3$ & $(\mathrm{JA})_{12.26}$ & IIa & - & - & I9 & 6 & - & - & $r_{3}$ & 4 & 3 & 45 \\
\hline 14 & $(\mathrm{AJ})_{102.2}$ & $\mathrm{IIa}$ & - & - & II & 5 & - & - & 5 & - & - & $2 \mathrm{I}$ \\
\hline 15 & $(\mathrm{JA})_{11.21}$ & IIa & - & - & 8 & 3 & - & - & - & 2 & I & $\mathrm{I} 4$ \\
\hline 16 & $(\mathrm{JA})_{12,11}$ & IIa & - & - & 2 & 4 & - & - & 2 & - & - & 8 \\
\hline I7 & $(\mathrm{JA})_{12.75}$ & IIa & - & - & $3 \mathrm{I}$ & I3 & - & - & I & 8 & - & 53 \\
\hline 18 & $(\mathrm{JA})_{12.4}$ & IIa & $\dot{-}$ & - & 26 & 8 & - & - & 6 & - & - & 40 \\
\hline 19 & $(\mathrm{JA})_{12,2}$ & IIb & - & - & - & 78 & 一 & - & 17 & - & - & 95 \\
\hline 20 & $(\mathrm{JA})_{11.8}$ & II $\mathrm{Ib}$ & - & - & - & Io & - & - & 8 & - & - & 18 \\
\hline 21 & $(\mathrm{JA})_{12.80}$ & IIb & - & - & - & II & - & - & 3 & - & 8 & 22 \\
\hline 22 & $(J A)_{21.78}$ & IIIa & - & - & - & - & $3 \mathrm{I}$ & 12 & II & - & - & 54 \\
\hline 23 & $(J A)_{11.79}$ & IIIa & 一 & - & - & - & Ig & 7 & 15 & 8 & 2 & $5 I$ \\
\hline 24 & $(\mathrm{JA})_{11,18}$ & IIIa & - & - & - & - & 28 & 8 & 12 & 5 & 2 & 55 \\
\hline 25 & $(\mathrm{JA})_{11.80}$ & IIIa & - & - & - & - & 34 & - & 8 & - & - & 42 \\
\hline 26 & $(\mathrm{JA})_{11.67}$ & IIIa & - & - & - & - & 39 & I5 & - & - & - & 54 \\
\hline 27 & $(\mathrm{JA})_{12.42}$ & IIIb & - & - & - & - & - & 47 & - & - & 6 & 53 \\
\hline 28 & $(\mathrm{JA})_{11.33}$ & IIIb & - & - & - & - & - & I5 & 7 & - & I & 23 \\
\hline 29 & $(\mathrm{~J} A)_{12.51}$ & IIIb & - & - & - & - & - & 26 & 9 & - & 3 & $3^{8}$ \\
\hline 30 & $(\mathrm{JA})_{11.28}$ & $\mathrm{Va}$ & - & - & - & - & - & - & 8 & 20 & I I & 39 \\
\hline $3 I$ & $(\mathrm{JA})_{11,50}$ & $\mathrm{Va}$ & - & - & - & - & - & 一 & - & $5^{2}$ & 16 & 68 \\
\hline 32 & $(\mathrm{IA})_{11.91}$ & $\mathrm{Va}(?)^{\prime}$ & - & - & 24 & 4 & - & - & $I$ & 8 & 4 & $4 \mathrm{I}$ \\
\hline
\end{tabular}

IIIa, is equivalent to the stippled "dusky" type hitherto designated IIIa; a comparison was made of the living specimens of the JA and EF IIIa types and ignoring the stippled distribution of the latter, one would pronounce the two to be the same; it is interesting to note that the " $\mathrm{b}$ " mem- 
ber of the III pair (distinguished especially by white eye instead of dark eye) shows its color more or less stippled. It should be said, too, that the type of EF duskies to which this JA type IIIa corresponds is the more "reddish" of the "duskies"; it was not at all like the more "bluish" or violet member of the pair of EF "duskies"; the JA type III looks "blue" compared to its associates but we must evidently not attribute this condition to a bluing gene. In the JA series, also, type III never contains II, nor does type II contain III, as is evidenced by the experimental data in table $\mathbf{r} 6$. Type I contains both II and III, however, and is considered to be the interaction effects of these. These results were unexpected, since the color of type II of the JA series is in quality different from that of the $A B$ and $E F$ series.

With these observations in mind it is not difficult to construct a factorial scheme to interpret the results:

\section{A PARENT}

$D$, same as in the $\mathrm{AB}$ and $\mathrm{EF}$ series.

$r$, absence or allelomorph of $R$.

$e$, absence or allelomorph of $E$.

$M$, factor determining dark eye color; also an intensifier of blade color.

\section{J PARENT}

$d$, absence or allelomorph of $D$.

$R$, factor for chromogen leading to the reddish pink anthocyanin of $J$.

$E$, factor for enzyme capable of converting chromogens into anthocyanin.

$m$, absence or allelomorph of $M$; in homozygous condition $m$ determines the white-eyed condition.

Table I 7 lists the possible factorial combinations for this scheme, with the phenotype of each combination and the number of times it is expected to occur in every 256 individuals. The last column of table $\mathrm{I}_{5}$ lists alongside of the observed figures the numbers to be expected in every 217 individuals; a comparison of the observed and calculated numbers shows that the correspondence between theory and fact is fairly close. 
TABLE I7

The possible factor combinations for the $F_{2}$ generation of the $J A$ series.

\begin{tabular}{|c|c|c|c|c|c|}
\hline $\begin{array}{c}\text { Factor } \\
\text { combinatio }\end{array}$ & & & $\begin{array}{l}\text { Phenotypic } \\
\text { formulae }\end{array}$ & Phenotype & $\begin{array}{c}\text { Theoretical } \\
\text { numbers }\end{array}$ \\
\hline $\begin{array}{l}E\left\{\begin{array}{l}D \\
i \\
d\end{array}\right. \\
e\left\{\begin{array}{l}D \\
d\end{array}\{\right.\end{array}$ & $\begin{array}{l}R \\
r \\
R \\
r \\
R \\
r \\
R \\
r \\
\end{array}$ & $\begin{array}{l}M \\
m \\
M \\
m \\
M \\
m \\
M \\
m \\
M \\
m \\
M \\
m \\
M \\
m \\
M \\
m \\
\end{array}$ & $\begin{array}{l}E D R M \\
E D R m \\
E D M M \\
E D r m \\
E d R M \\
E d R m \\
E d r M \\
E d r m \\
e D R M \\
e D R m \\
e D r M \\
e D r m \\
e d R M \\
e d R m \\
e d r M \\
e d r m \\
\end{array}$ & $\begin{array}{l}\text { Ia } \\
\text { Ib } \\
\text { IIIa } \\
\text { IIIb } \\
\text { IIa } \\
\text { IIb } \\
\text { Va } \\
\text { Vb } \\
\text { IV } \\
\text { IV } \\
\text { IV } \\
\text { IV } \\
\text { IV } \\
\text { IV } \\
\text { IV } \\
\text { IV } \\
\end{array}$ & $\begin{array}{r}81 \\
27 \\
27 \\
9 \\
27 \\
9 \\
9 \\
3 \\
27 \\
9 \\
9 \\
3 \\
9 \\
3 \\
3 \\
1 \\
\end{array}$ \\
\hline
\end{tabular}

GILBERT (I915) briefly described the results of three hybridizations in Phlox Drummondii in all of which a variety called "Carnea" was the pollen parent. From the colored plate accompanying his article it is obvious that his "Carnea" is like the J strain of my cultures; his seed parents were different, none of them bearing completely white flowers. One of his crossings gave $F_{2}$ results that make interesting comparison with the JA data presented above. He crossed his "Carnea" to a variety he says was known commercially as "Coccinea." This is described and pictured as bluish lilac with a dark eye. His plate D shows it to closely resemble the type IIIa ("dusky") already described. His $F_{1}$ flowers were what would be expected if my J or type IIb and "dusky" were crossed, i.e., a brilliant carmine, and resembling the $F_{1}$ in my JA series. GILBERT's $F_{2}$ generation of I I 5 plants comprised seven types; his plate would seem to prove that five of these types closely corresponded to or were identical with the types Ia, Ib, IIa, IIb, and IIIa of this paper. A sixth type with formula in the text including factors " $e e$ " (= white eye) and described as white, was pictured as a dark-eyed white. His seventh type is described and pictured as a dark-eyed white and was reported once in the $\mathrm{I}_{5}$ plants. Assuming that his sixth type was as his text described, Gilbert secured six of the nine types which are here re- 
ported for the JA series. The total absence in GilberT's cultures of a type like IIIb is surprising as is also the fact that the faintly colored independent types were not reported.

To interpret these results GILBERT supposed three factors necessary (with their recessive allelomorphs), (I) a factor for dark eye, (2) a factor for blue pigment, and (3) a distinct and independent "red" factor carried by the "Carnea" (=J) parent; these factors, in general, correspond to the writer's $M, D$, and $P$, respectively. GILBERT did not expressly state that the bright carmine was an interaction product of the factors for his dusky and reddish-pink sorts, but his genetic formulae imply this.

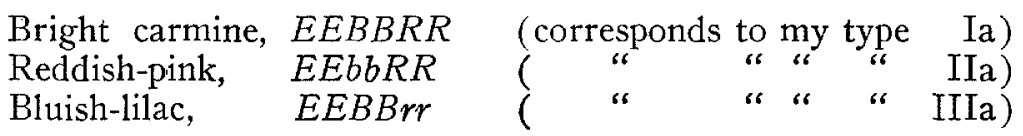

GILBERT carried none of his crosses to the $F_{3}$ generation so that he could not know from actual breeding that his reddish-pink never carried the gene for bluish-lilac, nor that the bluish-lilac never threw the reddish-pink, and that the heterozygous carmines could give both in the next generation thus pointing to the reddish-pink and bluish-lilac as resolution products.

In another of GiLBERT's crosses, he records an unexpected preponderance of white "which is unaccounted for." An explanation of this condition has been presented above in the exposition of the results of the $\mathrm{AB}$ series.

SOME SIMPLER CASES OF COLOR INHERITANCE IN PHLOX DRUMMONDII

The crossing of white-eyed tyrian rose $(P)$ and rohite-eyed pink

The line to which the $\mathrm{P}$ parent belonged has been carried on in pedigree culture in small numbers from season to season. No deviations from type have been noticed. In this $P$ strain the flowers are white-eyed with outer blade about a brilliant tyrian rose. The $\mathrm{J}$ type has already been described and pictured. The two individuals used as parents were crossed reciprocally giving seed for an $F_{1}$ generation of 12 plants; the flowers of the $F_{1}$ generation were all indistinguishable from those of the inbred $P$ strain.

Three of the $F_{1}$ plants furnished seed for an $F_{2}$ generation of 218 plants grown in 1918 . The $F_{2}$ group presented a sharp segregation into 
the two parental types, there having been $165 \mathrm{P}$ type to $53 \mathrm{~J}$ type. On a simple unifactorial basis expectation calls for $163.5 \mathrm{P}$ type to 54.5 $\mathrm{J}$ type. The correspondence, therefore, is very close.

By the conventional manner of Mendelian interpretation these experimental results would lead to the statement, probably, that we have obtained a definite idea of the specific difference between $\mathrm{P}$ and $\mathrm{J}$, that a factor in the $\mathrm{J}$ parent conditioning the reddish-pink $\mathrm{J}$ coloration is allelomorphic to a different factor in the $\mathrm{P}$ parent making for the carmine color. It would seem that the matter is not so simple as it appears, however. The segregation, of course, indicates a difference of some kind, but gives us no idea of the nature of the difference. The evidence on which this assertion is based was secured in the JA series; the P type really arose there anew following hybridization and recombination and was designated as type $\mathrm{Ib}$. The $\mathrm{P}$ strain was like the slightly darker variants of type $\mathrm{Ib}$ in the JA series. We learned there that Ib (and, hence, supposedly, P) is due to the composite or complementary effects of the factors for J (=IIb) and for the stippled mallow pink (=IIIb); that is $\mathrm{P}=\mathrm{J}$ (IIb) + IIIb. We inferred also that $\mathrm{J}$ never carries IIIb; and that the types that correspond to $\mathrm{P}$ and $\mathrm{J}$ both carry the gene for the $\mathrm{J}$ pigmentation. The hybrid between $\mathrm{P}$ and $\mathrm{J}$ must have been, therefore, homozygous for the factor conditioning $J$, and the segregation of $J$ in 25 percent of the $F_{2}$ in this JP series does not point to the real difference between $J$ and $P$. The real difference between $P$ and $J$, which is the presence of the complementary gene for mallow coloration, i.e., for type IIIb (present in $\mathrm{P}$ and lacking in $\mathrm{J}$ ), we know from our previous results in the IA series, but would probably have never even suspected from the results of crossing $J$ and $P$. All gametes of the $F_{1}$ generation (in the JP series), then, contained the factors for producing the J type of color; half of these in addition held the factor for the IIIb type of coloration revealed in the JA series and half lacked the latter; all $F_{2}$ zygotes of the $\mathrm{P}$ type must have carried the gene for IIIb color and all $\mathrm{J}$ zygotes presumably lacked this factor. We arrive thus at a seemingly paradoxical position: the $53 \mathrm{~J}$ segregates of the $F_{2}$ generation indicated a feature in which the parents were similar and the real difference was masked, for wherever the really differentiating factor for the mallow pink color appeared it was compelled to give a full-colored interaction product, because of the homozygous condition of the factor for the $J$ color ; and the absence or allelomorph of this factor for mallow-pink would allow the unchanged $\mathrm{J}$ color to appear. 
The results of crossing $\mathrm{P}$ and $\mathrm{J}$, therefore, pointed to a unifactorial difference but, in themselves, really furnished no clue as to the real nature of the difference.

\section{The genetic relationship of rithite $(A)$ and cream $(F)$}

Both parents were from pedigree lines grown in considerable numbers during several seasons and were known to be breeding true-the former, strain A, for completely white flowers, and the latter, strain F, for completely cream-colored flowers. Various members of the two types or strains were crossed giving seed for an $F_{1}$ generation of 47 plants; all $\mathrm{F}_{1}$ hybrids were completely white and indistinguishable from the A parent. Reciprocal hybrids were included but the $F_{1}$ plants were white no matter whether the seed parent was white or cream.

Seven of the $F_{1}$ individuals provided seed for an $F_{2}$ generation of I69 plants; the group presented a simple segregation into I 32 white and 37 cream. The expectation for a monomeric difference in the case of I69 individuals is $I 26.75: 42.25$. The fit of the theoretical to the actual is close enough to warrant postulating a single factorial difference operating to distinguish the white from the cream.

\section{The genetic relationship of white with dark eye $(B)$ and cream without dark eye $(F)$}

Various individuals of both types were crossed reciprocally. The parents were from lines which have been for several seasons in pedigree culture and known to be true to their respective types. Reciprocal hybrids were identical. A total of $67 \mathrm{~F}_{1}$ hybrids bloomed during I9I 7 and I9 18 , and all were similar, bearing white flowers with dark eyes, resembling the $B$ parents.

Several $F_{1}$ plants gave seed for an $F_{2}$ generation of $2 I_{3}$ individuals. Four sharply distinct types appeared among these $\mathrm{F}_{2}$ plants, the types and their numbers being given in table 18 .

TABLE 18

Actual and theoretical composition of the $F_{2}$ generaton from the cross of $B$ and $F$.

\begin{tabular}{c|c|c}
\hline \multicolumn{1}{c|}{$\mathrm{F}_{2}$ types } & $\begin{array}{c}\text { Observed } \\
\text { numbers }\end{array}$ & $\begin{array}{c}\text { Calculated } \\
\text { numbers }\end{array}$ \\
\hline Dark-eyed white $\ldots \ldots \ldots \ldots \ldots \ldots$ & $\mathrm{II} 2$ & $\mathrm{II} 9.8$ \\
Dark-eyed cream $\ldots \ldots \ldots \ldots \ldots \ldots$ & 37 & 39.9 \\
Completely white $\ldots \ldots \ldots \ldots \ldots \ldots$ & 47 & 39.9 \\
Completely cream $\ldots \ldots \ldots \ldots \ldots \ldots$ & 17 & 13.3 \\
\hline Total $\ldots \ldots \ldots \ldots \ldots \ldots \ldots \ldots$ & 213 & 212.9 \\
\hline
\end{tabular}


Obviously two independent factorial differences are at work in this case, the factor $W$, a dominant one, determining the white color of the plastids; its allelomorph, $w$, when homozygous, causes the cream color of the plastids. The other factor has already been encountered in the JA series, i.e., $M$, which causes the appearance of an anthocyanin eye at the centre of the flower; its allelomorph, $m$, is responsible for the colorless condition at the centre. In the last column of the table the expectations on such a basis are entered.

\section{CONCIUSIONS AND SUMMARY}

I. Since the introduction of Phlox Drummondii into culture less than 85 years ago a large number of marked variations has occurred, offering good opportunities for the genetical analysis of the species.

2. The distinguishing features of the several varieties upon which the present report is based, and their cultural designations (not to be confused with the factorial symbols) are as follows:

$\begin{array}{ll}\text { Cuspidate flowers } & \text { L } \\ \text { Funnel-shaped flowers } & \text { I } \\ \text { Completely white flowers } & \text { A } \\ \text { Dark-eyed white flowers } & \text { B } \\ \begin{array}{l}\text { Dark-eyed brilliant carmine or pome- } \\ \quad \text { granate purple flowers }\end{array} & \text { E } \\ \text { Completely cream flowers } & \mathrm{F} \\ \text { White-eyed reddish pink } & \text { J } \\ \text { White-eyed tyrian rose } & \mathrm{P}\end{array}$

3. An hereditary variation named var. cuspidata has arisen with much reduced corolla limb bearing on each lobe of the corolla two short lateral teeth and one long median tooth. A difference of a single gene distinguishes the entire-petalled from this cuspidate-petalled kind. An independent factor or factors (for breadth of lobes) interacts with the cuspidata and alters the character of the side teeth.

The fimbriata "variety" is merely a simple monoheterozygote of the entire and cuspidata types; it represents the only case of non-dominance for a factor, thus far known in Phlox Drummondii. The hybrid nature of fimbriata necessitates certain taxonomic amendments, indicated in the presentation.

The cuspidata gene would seem to act (chiefly) to decrease the rate of epidermal growth, this inhibition being weaker in three locations. The factorial symbol $I_{a}$ is suggested to designate this factor. 
4. Another hereditary variation in the form of the flower is represented by the funnel-shaped phloxes; a single factorial difference distinguishes the funnel-shaped from the salver-shaped condition normal for the Phlox genus. The factor $S$ is presumed to determine the salver shape and its allelomorph $s$, which is completely recessive, the funnel shape. Two other grades of corolla expansion were found. The factor $s$ itself or some other uninvestigated gene closely linked with it, causes the colored funnel-shaped flowers to appear white-streaked.

5. There are pairs or sets of complementary factors in Phlox Drummondii. In some cases in addition to the compound or interacting effect, the individual members of the pairs or sets are capable of separate and distinct somatic expression. In other cases each pair or set of genes becomes evident only in the single compound character, the components remaining latent (invisible or cryptomeric) when not present together.

a. The crossing of the strains $A$ and $B$ (in both of which the flower blades are white) and of $A$ and $J$ (the former with white blade and the latter with light pink) gave in each case a surprisingly different fullcolored $\mathrm{F}_{1}$ type.

b. The simultaneous presence of three factors is necessary before a simple blade color can develop; the $\mathrm{F}_{1}$ hybrid of $\mathrm{A}$ and $\mathrm{B}$ proved heterozygous for all three of these necessary factors as evidenced by the large proportion of $F_{2}$ white-bladed plants and the character of the families from $\mathrm{F}_{2}$ colored plants. The three factors are conceived to be, first, one, $P$, that leads to chromogen formation; secondly, one $E$, that leads to the production of an enzyme; and lastly one that leads to the production of an activator of the enzyme, $A$.

c. The simple type of blade color caused by the presence of the minimum complement of the three necessary factors varies, depending presumably on the character of the chromogen base present. One (type IIb of the $\mathrm{AB}$ and $\mathrm{EF}$ series) is thought to be due to the simultaneous presence of genes $E$ and $A$, and the chromogen-producing gene $P$. A second simple type of blade color, the "dusky," both stippled and unstippled, is supposed to be due to the same factors, $E$ and $A$, acting on a different chromogen due to the factor $D$. A third of the simple types is considered due to the factors $E$ and $A$ acting on a chromogen $R$.

d. The $F_{2}$ and $F_{3}$ data led to the following inferences: Blade color type due to $P E A+$ type due to $D E A=$ a distinct full-colored type designated $\mathrm{Ia}$ in the account of the $\mathrm{AB}$ and $\mathrm{EF}$ series and in plate $\mathrm{I}$. Ia is 
considered to be due merely to the interaction of factors $P$ and $D$ in the presence of $E$ and $A$; no factors that may be called specific for the Ia type are in play. Similarly, the type due to factors $R E A+$ the type due to $D E A$ give a full-colored type designated $\mathrm{Ia}$ in the $\mathrm{JA}$ series and in plate 2. These generalizations are based on the character of the $F_{3}$ results; the critical test, the actual putting together of the simple types by hybridization has not been accomplished.

6. Modifying factors have been in evidence:

a. The $A B$ and EF series of plants exhibited a bluing factor (or linked pair of factors(?)), independent of the essential color producers, which doubled the number of the color groups; for every "reddish" group it made a corresponding more "bluish" group.

b. A simple dominant diluting factor of minor effect occurred in the EF series,-designated $D_{i}$.

c. A minor factor, slightly reddening and intensifying simultaneously was referred to briefly in the EF series,--designated $D_{e}$.

d. The dark-eye factor, $M$, led to intensification of the blade color.

7. Dark-eyed forms differ from the light-eyed forms by a single factorial difference,- designated $M$. Its allelomorph causes the white eye.

8. The cream-colored condition is a simple recessive to the white-colored; gene $W$ determines whiteness and its allelomorph, $w$, causes the cream. The same relationship of white to cream is inferred from GiLBERT's published results.

9. The chromosome number in Phlo.t Drummondii is I $_{4}$ for the cells of the root-tip.

\section{LITERATURE CITED}

Bateson, W., I9I3 Mendel's principles of heredity. xiv $+4 \mathrm{I} 3$ pp. Cambridge, England: Cambridge Univ. Press.

Bateson, W., and Saunders, E. R., Ig02 Reports to the Evolution Committee of the Royal Society. I. Experimental studies in the physiology of heredity. I6o pp. Bateson, W., Saunders, E. R., and Punnett, R. C., I905 Reports to the Evolution Committee of the Royal Society. II. I3I pp.

1906 Reports to the Evolution Committee of the Royal Society. III. $53 \mathrm{pp}$.

Igo8 Reports to the Evolution Committee of the Royal Society. IV. 60 pp.

BAUR, E., I9I4 Einführung in die experimentelle Vererbungslehre. viii $+40 \mathrm{op}$. Berlin: Gebrüder Bornträger.

BRAND, A., I907. Polemoniaceae. Das Pflanzenreich. iv: 250, pp. 70-72.

Correns, C., I9I2 Die neuen Vererbungsgesetze. viii +75 pp. Berlin: Gebrüder Borntraeger.

DeVries, H., Igoo Sur la loi de disjonction des hybrides. Comptes rendus 130: 845-847. 
EAST, E. M., I9I2 Inheritance of color, in the aleurone cells of maize. Amer. Nat. $46: 363-365$.

EAST, E. M., and Hayes, H. K., IgII Inheritance in maize. Connecticut Agric. Exp. Sta. Bull. 167, I42 pp.

Emerson, R. A., I918 A fifth pair of factors, $A a$, for aleurone color in maize and its relation to the $C c$ and $R r$ pairs. Cornell Agric. Exp. Sta. Memoir I6, pp. $231-289$.

Gilbert, A. W.,I915 Heredity of color in Phlox Drummondii. Jour. Agric. Res. $4: 293-302$.

Gregory, R. P., I9II Experiments with Primula sinensis. Jour. Genetics $1: 73-132$.

Hooker, W. J., I835 Phlox Drummondii. Mr. Drummond's Phlox. Curtis's Bot. Mag., N. S. $9:$ Pl. $344 I$.

Jennings, H. S., I9I9 Organic evolution. American Year Book for 1918. New York: D. Appleton \& Co.

Kelly, J. P., I9I5 Cultivated varieties of Phlox Drummondii. Jour. N. Y. Bot. Gard. 16: I79-I9I.

I9I7 Further observations on Phlox Drummondii. Jour. N. Y. Bot. Gard. $18: 83-86$.

LEAKE, H. M., I9II Studies in Indian cotton. Jour. Genetics $1: 205-272$.

RidGWAY, R., Ig12 Color standards and color nomenclature. Washington, D. C.: Published by the author.

Shull, G. H., 1910 Germinal analysis through hybridization. Proc. Amer. Philos. Soc. $49: 28 \mathrm{I}-296$.

I912 The primary color factors of Lychnis and color inhibitors of Papaver rhoeas. Bot. Gaz. 54: 120-135.

Sprenger, C., I888 Phlox Drummondii fimbriata und Phlox Drumm. cuspidata. Gartenflora $37: 426-428$.

Thistreton-Dyer, W. T., 1897 The cultural evolution of Cyclamen latifolium. Proc. Royal Soc. 61 : 135-147.

Wheldale, M., Ig16 The anthocyanin pigments of plants. $x+318$ pp. Cambridge, England: Cambridge Univ. Press.

Wittmack, L., I888 Grashoffs neue Varietäten von Phlox Drummondii Hook. Gartenflora $37:$ I-4. Pl. I264. 